1 Visualized experiments on residual oil 2 classification and its influencing factors in 3 waterflooding using micro-computed 4 tomography



${ }^{1}$ Correspondence should be addressed to Jiajun Peng at jiajunpeng@stu.swpu.edu.cn and Shuyu Sun at shuyu.sun@Kaust.edu.sa 
Journal of Energy Resources Technology

\section{Jianjun Liu}

34 State Key Laboratory of Geomechanics and Geotechnical Engineering, Institute of Rock and Soil Mechanics,

35 Chinese Academy of sciences

36 Xiaohongshan, Wuchang, Wuhan 430071, P. R. China

37 jjliu@whrsm.ac.cn

38 


\section{Abstract}

Pore-scale mechanism of the waterflooding process contributes to enhanced oil recovery (EOR), which has been widely emphasized in the petroleum industry. In this paper, pore-scale waterflooding experiments are carried out on mixed-wetted natural sandstone and 3D printed sandstone using micro-computed tomography. The high-resolution images of oil/water distribution in different stages of waterflooding cycles are acquired. The classification of residual oil after waterflooding is conducted using the shape factor and Euler Number, which represents the shape and spatial connectivity, respectively. The in-situ contact angles are measured on the segmented images and the pore-scale wettability of these two samples is analyzed. Then, the effects of pore structure, micro-fracture and wettability on the distribution of the patterns of residual oil are analyzed. The results indicate that the types of isolated, cluster, network, and film (only for natural sample) are the main forms of residual oil patterns after the waterflooding process. The negative correlation between the shape factor and the Euler number of the typical oil blocks are presented. The effect of wettability and pore geometry on the morphology of the oil/water interface is quantitatively studied. The capillary pressure is the key factor for the formation of the residual oil blocks, the morphology of which is controlled by both wettability and pore geometry.

\section{Introduction}

Because of worldwide reliance on petroleum, enhancing oil recovery is the key concern in the petroleum industry[1]. With the advantages of simple operation and low cost, the waterflooding process has been regarded as one of the most common methods for secondary oil recovery all over the world $[2,3]$. However, according to the production data of oil fields, the residual oil after waterflooding accounts for $70 \% \sim 80 \%$ in the reservoir $[4,5]$. Thus, many experimental efforts at core-scale or pore-scale have been made to reveal the two-phase flow mechanism and the distribution of residual oil. Compared to the traditional core test in the laboratory, the pore-scale waterflooding experiments adopting high-resolution imaging technology is able to investigate the fluid flow and distribution in the micro-pores, and evaluate the corresponding macro flow characteristics. These techniques include traditional optical technology, nuclear magnetic resonance (NMR), laser scanning confocal microscopy (LSCM), and micro-computed tomography ( $\mu-\mathrm{CT})$.

The traditional optical technology obtains 2D images from thin slices of rock, which neglects the spatial connectivity of the pores in natural rock [6,7]. The NMR technology distinguishes oil from water in pores by adding water-soluble paramagnetic ions into water [8-10]. However, it would be invalid when there are ferromagnetic substances in rock. The LSCM technology utilizes the different fluorescence characteristics of oil/water to obtain two-dimensional images of oil/water distribution by point-by-point and layer-by-layer scanning with point light source. Then three-dimensional images of oil/water distribution can be reconstructed using the serial slices images. The resolution of this technology reaches hundreds of nanometers. However, the thin thickness of the imaged core limits the application of this technology $[11,12]$. The $\mu$-CT technology uses the attenuation characteristic of the X-ray when it transmits the sample to image the internal structure of the sample [13-15]. Compared with other technologies, the $\mu$-CT technology avoids reaches the micron or even nanometer level [16]. 
In recent years, based on the $\mu$-CT technology, the morphology and distribution of the residual fluids, the pore-scale wettability, and the capillary pressure have been quantitatively classified and analyzed. Andrew et al. [17] investigated the pore-scale arrangement and distribution of trapped $\mathrm{CO}_{2}$ blocks in a limestone after $\mathrm{CO}_{2}$ flooding using $\mu-\mathrm{CT}$ and analyzed the size and quantity of the trapped $\mathrm{CO}_{2}$ blocks. A power function relationship between the size and quantity of the remaining fluid blocks was proposed. Wang et al. [18] studied the oil/water distribution in the water-wetted sand pack during waterflooding, polymer flooding, and preformed particle gel flooding. The quantity, average volume, contact area ratio, and shape factor of the residual oil were analyzed. Gu et al. [19] used the micro computerized tomography to visualize the irreducible water distribution in a low-permeability sandstone and analyzed the difference of the irreducible water occurrence mode between the pore system and the throat system. The results showed that the irreducible water principally existed in the corner of the pores in the pore system and was dominated by the water film in the throat system. Scanziani et al. [20] investigated the in-situ distribution characterization of the immiscible three-phase flow at the pore scale in a water-wet carbonate rock by micro computerized tomography, and found that the brine occupied the smallest pores, gas the biggest, while oil occupied pores of intermediate size and is displaced by both water and gas. Li et al. [21] conducted the similar waterflooding experiment on six water-wetted sandstones and classified the residual oil as membranous flow, droplet flow, columnar flow, multi-porous flow, and clustered flow using shape factor, contact ratio, and Euler number, etc. The clustered flow was believed to possess high relative permeability and strong producing capacity. Using the same method, Li et al. [22] further investigated the dynamic oil cluster during drainage and imbibition, and found that the size and distribution of connected clusters and disconnected globules of the nonwetting phase were significantly influenced by wettability. Guo et al. [4] adopted $\mu$-CT to image the oil/water distribution in four water-wetted sandstones during waterflooding and analyzed the effect of pore structure on displacement efficiency and oil blocks morphology. The results showed that the variation of the oil block pattern and the oil recovery were larger in rock with simple pore structure and good connectivity during displacement. Gu et al. [5] visualized the oil/water distribution during the spontaneous imbibition of lowpermeability water-wetted sandstone by $\mu$-CT and classified the micro-occurrences of residual oil into network, cluster and isolated. The residual oil of the network shape and cluster shape were considered to be easier to recover for large volume and good connectivity. Yang et al. [23] employed the shape factor and Euler number to classify the residual oil, and found that the distribution patterns of oil blocks continuously changed during waterflooding.

In these studies, the residual oil in the waterflooding process was statistically analyzed by related factors such as shape factor, contact ratio, and Euler number. The results show that the micro-patterns of the residual oil were constantly changing during displacement. The variation of the oil pattern and recovery is larger in rock with simple pore structure and good connectivity. A power-law distribution between size and the amount of the residual fluid block has been found in these studies. However, these researches are mainly obtained in water-wetted rocks, while most natural reservoirs all around the world are mixed-wetted [24,25]. Furthermore, the reason for the occurrence of the oil cluster with different shape patterns is still unclear.

Wettability reflects the complex interactions of fluid and rock and determines the microscopic distribution of fluid phases in the pore space [26]. Therefore, the qualitative and quantitative analysis and characterization of wettability has always been the goal of researches. The pore-scale wettability of rocks, characterized by the in-situ contact angle between oil and water in the pore space, was determined by $\mu$-CT 
images [27]. Traditionally, contact angles had been measured on smooth mineral surfaces, such as quartz and calcite, which represented sandstone and carbonate, respectively [28,29]. However, the equilibrium measurements of the contact angles on the smooth mineral surface are not accurate since rocks have complex minerals and rough grain surfaces [30]. Based on $\mu$-CT images of oil/water distribution, AlRatrout et al. [31] firstly developed an automated method to measure the in-situ contact angle. The results showed the wide range of the pore-scale wettability, the overall performance of which is consistent with traditional measurement result. Subsequently, the codes were widely used for in-situ contact angle measuring. Alhammadi et al. [32] measured the in-situ contact angle and analyzed the effect of pore-scale wettability on oil recovery. The highest oil recovery for the mixed-wetted sample appeared with an average contact angle close to $90^{\circ}$. Alratrout et al. [33,34] acquired the contact angles in three carbonate rocks with different wettability after waterflooding, and found that both the contact angle and interfacial curvature increased with the local roughness of grains, but not the surface roughness of the rock. Akai et al. [35] measured the in-situ contact angles of every pore in the mixed-wetted carbonate rock and adopted the results to simulate the dynamic displacement. The results indicated that the in-situ contact angles helps to improve the simulation accuracy.

Meanwhile, some scholars used the $\mu$-CT images of fluid distribution to obtain the pore-scale distribution of the capillary pressure. Armstrong et al. [36] firstly employed the $\mu$-CT images of oil/water distribution to calculate the curvature and capillary pressure during the imbibition and displacement process of the glass bead. The method was verified by the measurement of the pressure transducer. Subsequently, the method was widely applied to the studies of the pore-scale capillary pressure distribution. Andrew et al. [37] adopted the method to measure the capillary pressure of each residual $\mathrm{CO}_{2}$ block after water displaced $\mathrm{CO}_{2}$, and the inversely proportional relationship between the capillary pressure and the largest radius of throat surrounding the residual $\mathrm{CO}_{2}$ block has been discovered. Garing et al. [38] also used the method to measure the capillary pressure distribution of trapped residual air block during gravity-driven brine imbibition, and found that the sub-micron resolution was more favorable to lead these investigations of fluid identification and capillary pressure in real rocks. Lin et al. [39] measured the capillary pressure in the steady-state multiphase flow through a homogeneous sandstone and observed a detectable gradient in both saturation and capillary pressure along the flow direction. It is believed that the capillary pressure is controlled by the surface wettability and the pore size, however, rare studies has been conducted to reveal the effects on the morphology of the residual oil block.

In this study, the pore-scale waterflooding experiments are conducted on two mixed-wetted sandstones by using micro-computed tomography. Based on the acquired $\mu$-CT images of oil/water distribution, the characterization of pore scale wettability is presented. The patterns of the residual oil are classified using the shape factor and Euler number. Then the effects of the wettability and pore geometry on the morphology of the residual oil block are analyzed.

\section{Experiments}

\subsection{Material}

The waterflooding experiments are conducted on two cylindrical samples of natural sandstone and 3D printed sandstone. The natural sample is marine tight sandstone from Wujiang block (located in the Zhanjiang, south China), containing $86 \%$ quartz and $14 \%$ feldspar. And the 3D printing sample is homogeneous 
sandstone, containing $98 \%$ quartz sand grains with the average size of $60-100 \mu \mathrm{m}$, as well as $2 \%$ binder. The physical properties of the two samples are shown in Table 1. According to the sessile drop experiment, both samples are mixed-wetted, as is shown in Fig. 1. After the $\mu$-CT imaging, the pore diameter distribution of the two samples are obtained by calculating the diameter of the maximum inscribed sphere in pores, as shown in Fig.2.

In this study, the brine solution is made from deionized water with $\mathrm{NaCl}, \mathrm{CaCl}_{2}$, and $\mathrm{MgCl}_{2}$. The composition of the brine is shown in Table 2 . And the oil phase is prepared by dissolving 9 vol\% of Iodohexadecane in coal oil. With high atomic weight and large X-ray attenuation coefficient, Iodohexadecane helps to enhance the contrast between oil and water in the $\mu$-CT images. The waterflooding experiments are conducted under the temperature of $25^{\circ} \mathrm{C}$. The densities of water and oil are $1.06 \mathrm{~g} / \mathrm{cm}^{3}$ and $0.96 \mathrm{~g} / \mathrm{cm}^{3}$, respectively. The dynamic viscosity of the brine and oil are $1.16 \mathrm{cp}$ and $1.72 \mathrm{cp}$, respectively. The surface tension coefficient between oil and water is $0.048 \mathrm{~N} / \mathrm{m}$. The maximum capillary number is $4.78 \times 10^{-7}$ when the oil is injected into the core at a flow rate of $0.00159 \mathrm{ml} / \mathrm{min}$.

\subsection{Experimental Methodology}

The schematic diagram of the waterflooding experimental system combining with $\mu$-CT is shown in Fig. 3. The experimental apparatus is shown in Fig. 4, which is composed of the displacement system, the microcomputed tomography scanner, and the core holder. The differential pressure transducer of the displacement system is used to detect the pressure difference between the inlet and outlet of the core holder. During the waterflooding process, the displacement is completed when the pressure difference is stable.

The experimental workflow is as follows:

(1) A confining pressure of $0.82 \mathrm{MPa}$ is maintained within the core holder to avoid the leakage of the injected fluids from the contact areas between the core and rubber sleeves in the experiment.

(2) The brine is injected into the core at a constant flow rate of $0.00155 \mathrm{ml} / \mathrm{min}$. When the displacement is completed, the initial water distribution is obtained by $\mu$-CT scanning.

(3) The oil is injected into the core at a constant flow rate of $0.00159 \mathrm{ml} / \mathrm{min}$ to simulate the formation of the reservoir. The distribution of oil and irreducible water is imaged by the $\mu$-CT scanning.

(4) The waterflooding is conducted by injecting brine into the core at a constant flow rate of 0.0017 $\mathrm{ml} / \mathrm{min}$. When the displacement is finished, the distribution of residual oil and water is obtained by $\mu-\mathrm{CT}$ scanning.

The $\mu$-CT images of each stage are obtained by the Xradia MICROXCT-400. The voxel size is $4.437 \mu \mathrm{m}$ for natural sandstone and $4.366 \mu \mathrm{m}$ for $3 \mathrm{D}$ printed sandstone. And the full size of the reconstructed images is $988 \times 1011 \times 990$ for natural sandstone and $992 \times 1012 \times 992$ for $3 \mathrm{D}$ printed sandstone. Limited by the calculation conditions, a subvolume $966 \times 966 \times 600$ voxels for natural sandstone and $600 \times 600 \times 600$ voxels for $3 \mathrm{D}$ printed sandstone are analyzed, respectively.

\section{Image Processing and Analysis \\ 3.1. Image Processing}

The nonlocal-means filter is adopted to improve image quality, which protects the edge of the phase interface when reducing the majority of noise [40]. After filtering, the image is segmented into three phases (water, oil, and rock grains) using the watershed segmentation algorithm [41]. The results of the segmentation 


\subsection{Image Analysis}

\subsubsection{Wettability}

In this paper, the in-situ contact angle, which illustrates the wettability of the rock surface, is measured using an open source code by AlRatrout et al. [31]. The method mainly includes the following four steps: First, a multi-zone mesh, consisting of oil, water, and rock grains, is generated. Second, the surfaces of oil/water and water/rock, three-phase contact line are extracted. Third, the extracted surfaces are smoothed by a volume preserving Gaussian smoothing and a local uniform curvature smoothing. Fourth, the contact angle on each vertex that belongs to the contact line is computed. The contact angle is obtained by Eq. (1) [31],

where $\boldsymbol{n}_{\mathbf{1}}$ is the unit normal vector of the oil/water surface, $\boldsymbol{n}_{\mathbf{2}}$ is the normal vector of the water/rock surface.

\subsubsection{Porosity and Saturation}

Porosity refers to the ratio of the pore volume to the total volume of the rock. Saturation is the volume fraction of oil and water in the pores. For the segmented images, these parameters can be determined by counting the pixel volume of different phases.

$$
\theta=\pi-\cos ^{-1}\left(\boldsymbol{n}_{1} \cdot \boldsymbol{n}_{2}\right)
$$
Then all contact angles for the full sample are measured by iterative calculation along the contact line.$$
\text { . }
$$

$$
\begin{aligned}
& \phi=\frac{V_{p}}{V_{b}}=\frac{V_{p}}{V_{p}+V_{s}} \\
& S_{o}=\frac{V_{o}}{V_{p}} \\
& S_{w}=\frac{V_{w}}{V_{p}}
\end{aligned}
$$

where $\phi$ is the porosity, $S_{o}$ is the oil saturation, $S_{w}$ is the water saturation, $V_{b}$ is the total volume of the sample, $V_{p}$ is the volume of pore, $V_{s}$ is the volume of rock grain, $V_{o}$ is the volume of oil, and $V_{w}$ is the volume of water.

\subsubsection{Classification of Residual Oil Pattern}

This paper adopts the shape factor $(G)$ and Euler number $\left(E_{N}\right)$ to classify the residual oil blocks. The shape factor shows the sphericity of an oil block. The shape factor can be calculated by Eq. (5) [43]:

$$
G=\frac{6 \sqrt{\pi} V_{o i}}{S_{o i}^{1.5}}
$$

where $V_{o i}$ is the volume of the given oil block, $S_{o i}$ is the surface area of this oil block and $G$ is the shape factor of this oil block. For a sphere, the shape factor is 1 .

The Euler number $\left(E_{N}\right)$ describes the connected characteristics of an oil block. It can be obtained by Eq. (6) [44]: 


$$
E_{N}=b_{0}-b_{1}+b_{2}
$$

where $b_{0}$ is the number of isolated components, $b_{1}$ is the number of tunnels, $b_{2}$ is the number of voids.

As is listed in Table 3, combined with the shape factor $(G)$ and Euler number $\left(E_{N}\right)$, the residual oil blocks are mainly divided into four types: isolated, cluster, network, and film. The characteristics and classification of all types of residual oil blocks proposed in this paper are as follows:

(1) Isolated: The isolated pattern residual oil blocks (with regular structure and small volume) mainly distribute in small pores. Both the shape factor and Euler number of this type of residual oil blocks are approaching to 1 .

(2) Cluster: The cluster pattern oil blocks mainly distribute in the pore-throat chains with narrowly connected throats.

(3) Network: The network oil blocks are also produced by the narrow connected throats. Compared with the cluster pattern, network pattern residual oil blocks have a larger volume and better inner connectivity.

(4) Film: The film oil blocks mainly adheres to the oil-wetted wall of larger pores (especially fractures), with good connectivity but small volume.

\subsubsection{Capillary Pressure}

Based on the segmented images, the oil/water interface is first extracted. And then a smoothed surface is generated at the interface by using the generalized marching cubes algorithm [17]. Finally, the curvature is obtained by approximating the surface locally as a quadratic form [36].

$$
a x^{2}+b y^{2}+c z^{2}+2 e x y+2 f y z+2 g z x+2 l x+2 m y+2 n z+d=0
$$

where $a, b, c, d, e, f, g, l, m$, and $n$ are all constant coefficients. When the quadratic form infinitely approximates the triangulated surface, these parameters are the optimal solution. And the eigenvalues and eigenvectors of the quadratic form refer to the principal curvature values and the directions of principal curvature, respectively. Therefore, the mean curvature is the average of the two principal curvatures $k_{1}$ and $k_{2}$.

$$
k=\frac{k_{1}+k_{2}}{2}
$$

where $k$ is the mean curvature, $k_{1}$ and $k_{2}$ are the two principal curvatures, respectively. Finally, the capillary pressure can be obtained from the mean curvature using the Yang-Laplace equation.

$$
P_{c}=2 \sigma k
$$

where $P_{c}$ is the capillary pressure, $\sigma$ is the surface tension coefficient. The workflow of capillary pressure calculation is shown in Fig. 6.

\section{Results and Discussion}

\subsection{Wettability}

The contact angles are measured on a sub volume with $200 \times 200 \times 200$ voxels extracted from the images of oil/water distribution after waterflooding. The results are shown in Fig. 7. According to the histogram, the contact angles of both natural sandstone and 3D printed sandstone distribute in a wide range with the values 
272 both above and below $90^{\circ}$. The results shows the heterogeneity of wettability of rock at the pore scale, which

273 also indicates that the two samples are mixed-wetted. The results agree well with the contact angle test by 274 the sessile drop method.

The percentages of both the water-wetted and oil-wetted parts in the two samples are shown in Table 4. For natural sandstone, 65284 in-situ contact angles are available within the cropped subvolume and the average is $117^{\circ}$. For $3 \mathrm{D}$ printed sandstone, the number of in-situ contact angles is 72903 and the average is $95^{\circ}$. According to previous research findings [31,34,35], the natural sandstone is regarded as oil-wetted and the $3 \mathrm{D}$ printed sandstone is mixed-wetted at the macro scale. Thus, the macro scale wettability of the rocks is the combined effect of water-wetted pores and oil-wetted pores.

\subsection{Variation of Residual Oil Block Pattern}

Based on the images of oil/water distribution before and after waterflooding, the oil saturation and recovery are obtained by image analysis, as is shown in Table 5. It is found that the oil saturation of the natural sandstone decreases from $67.52 \%$ to $44.92 \%$ after waterflooding with the oil recovery of $9.15 \%$. For the $3 \mathrm{D}$ printed sandstone, the oil saturation decreases from $60.13 \%$ to $39.44 \%$ after waterflooding, and the oil recovery is up to $34.80 \%$.

To further analyze the differences of residual oil block patterns in two samples, we separated the residual oil into mutually independent oil blocks using 26 neighborhoods connectivity. According to Section 3.2.4, the patterns of the residual oil are classified into four types: isolated, cluster, network and film (only for natural sandstone) using the shape factor $(G)$ and Euler number $\left(E_{N}\right)$, as shown in Fig. 8 and Fig. 9.

The saturation of the four types of oil blocks is calculated and shown in Fig. 10. The main oil blocks of the natural sandstone are the network pattern and the cluster pattern before waterflooding, but they change into the network pattern and the film pattern after waterflooding. There is a micro-fracture with oil wettability in the natural sandstone, which leads to the increasing and high fraction of film pattern residual oils. For 3D printed sandstone, the main oil blocks change from network pattern and cluster pattern to only network pattern after waterflooding, which indicates the good connectivity of the pores. The volume of network pattern and cluster pattern oil blocks in both two samples obviously decreases, which indicates that this two kinds of patterns contribute to most of the oil recovery. The results demonstrate that the large connected oil blocks tend to break into smaller parts during the waterflooding process.

It is found that the volume of isolated pattern oil blocks holds constant in the natural sandstone but slightly increases in 3D printed sandstone during the waterflooding process. For the macro oil-wetted natural sandstone, the oil preferentially enters into these small pores, which results in a lot of isolated pattern oil blocks during the oil flooding process. In contrast, the water preferentially enters into the large pores during the waterflooding process. After waterflooding, the isolated pattern oil blocks in small pores are not swept, and the residual oil in the fracture and large pores is interconnected. According to the morphological principle, this residual oil is classified into the film pattern. Thus, the volume of isolated pattern oil blocks is constant in the natural sandstone after waterflooding. For the mixed-wetted 3D printed sandstone, the small discontinuous residual oil blocks are usually trapped in the corner of pores after waterflooding. This residual oil is often classified into the isolated pattern by using the morphological principle, which results in the increasing volume of isolated pattern residual oil blocks.

The correlation between the shape factor and the Euler number of the typical oil blocks is presented in 
Fig. 11. The results indicate that good connectivity of pores leads to the complex structure of the residual oil blocks, e.g. the network pattern and the film pattern. The network pattern accounts for large residual oil blocks, but the film pattern has great exploitation potential since its excellent connectivity (highly negative Euler number). The two types of patterns can be distinguished by the shape factor value. The optimized oil recovery will be obtained in the pores with regular shape and good connectivity. Power distribution between the shape factor and Euler number of residual oil blocks can be fitted on the curve, which shows the key influence of the pore connectivity on the shape pattern of the residual oil, as well as the oil recovery.

\subsection{Effect of Fracture on Waterflooding}

The distribution of oil/water in the fracture before and after waterflooding is shown in Fig. 12. It can be seen that there is a large amount of thin-film pattern oil, which adheres to the wall of the micro-fracture. The volume and the oil saturation of the fracture before and after the waterflooding process are listed in Table 6. The volume of the micro-fracture increases about $8.01 \%$.

The variation of the oil morphology in the fracture is shown in Fig. 13. the film pattern oil in fracture becomes thinner during waterflooding. The oil recovery of fracture is $23.84 \%$, which is higher than that of the whole sample. Combined with the residual oil morphology and the contact angle, the fracture is mainly oil-wetted. During the oil flooding process, the oil preferentially wets the wall of pores and advances to the outlet, which results in that a large amount of irreducible water is left in the center of the fracture. During the waterflooding process, the water preferentially advances along the irreducible water in the center of the fracture, which lead to that a part of oil is displaced by injected water. But after the water breaks through along the fracture, most of the film pattern residual oil still adheres to the wall of the fracture. Thus, for oilwetted reservoirs, it is necessary to take measures to put off the injected water breakthrough during the waterflooding process.

The cross section of the micro-fracture along the flow direction is presented in Fig. 14. The fracture is found to be propagated through the whole sample during the waterflooding, which increases the oil recovery in the fracture compared to the whole sample. After water breaks through the sample along the fracture, the oil in these small pores far from the fracture is nearly not swept. The breakthrough of the injected water in the fracture decreases the sweeping efficiency of the small pores in the neighborhood. Thus, the breakthrough of injected water is the main reason for the high water saturation of the producing fluids in the late stage of waterflooding. The expansion of the fracture increases the permeability of the reservoir, which benefits to produce oil. But the interconnected fractures tend to form the main leakage channels of injected water breakthrough, which decreases the sweeping efficiency of small pores in the neighborhood.

\subsection{Capillary Pressure of Residual Oil Block}

The distribution of capillary pressure of the network pattern and the film pattern residual oil blocks is shown in Fig. 15. The results indicate that in natural sandstone the capillary pressure mainly distributes in the range of $(-10.8 \mathrm{kPa}, 16.6 \mathrm{kPa})$ for network pattern residual oil blocks and in the range of $(-7.5 \mathrm{kPa}, 11.0 \mathrm{kPa})$ for film pattern residual oil blocks. For 3D printed sandstone, the capillary pressure of network pattern residual oil blocks mainly distributes in the range of $(-10.0 \mathrm{kPa}, 10.0 \mathrm{kPa})$.

The capillary pressure distribution in narrow throats and dead-end pores is shown in Fig. 16 and Fig. 17, respectively. The results demonstrate that in the narrow throats and dead-end pores, the capillary pressure is 
usually larger than that in neighboring large pores. Thus, water will flow along the low resistance path, which results in that the oil is trapped in these narrow regions of pores and throats.

Here, the orientation angle $\beta$ which describes the converging and diverging degree of the pore is introduced to analyze the effect of pore geometry on interface morphology of residual oil blocks. The effects of the contact angle $(\theta)$ and orientation angle $(\beta)$ on the interfacial morphology of the residual oil blocks are shown in Fig. 18. The results show that there are three types of morphology of the oil/water interface. First, the water is stopped in front of the throat at the inlet of flow and the oil/water interface is concave along the flow direction such as type A. Second, the water is stopped in back of the throat at the inlet of flow and the oil/water interface is convex along the flow direction such as type $\mathrm{C}$. Third, the water is stopped in back of the throat at the inlet of flow and the oil/water interface is concave along the flow direction such as type B. In which, the entire two-dimensional plane is divided into I, II, III by $\theta=\pi / 2+\beta$ and $\theta=\pi / 2-\beta$. The oil/water interface is flat in boundaries between these regions [45]. For type A, the high capillary pressure is a resistance for waterflooding in the strong oil-wetted or weak oil-wetted and small orientation angle inlet, which stop the moving of the injected water along the center of the throat. Fortype $\mathrm{C}$, the capillary pressure is a driving force for waterflooding, which advances the mobility of the water along the wetted surface and leads to the residual oil block in the middle of the pore. For type B, the weak wettability and large orientation angle lead to a concave oil/water interface in the inlet.

The selected 20 residual oil blocks mainly distribute in 5 regions as a, b, c, d, and e in Fig. 18. It is found that the oil/water interface is mainly controlled by the contact angle under strong wettability inlet $\left(\theta>130^{\circ}\right.$, $\left.\theta<50^{\circ}\right)$ such as the residual oil blocks in region a and e. Under the weak wettability inlet $\left(130^{\circ}>\theta>50^{\circ}\right)$ such as the residual oil blocks in region $\mathrm{b}, \mathrm{c}$, and $\mathrm{d}$, the oil/water interface is mainly controlled by the orientation angle. For the inlet with small orientation angle such as the residual oil blocks in region $\mathrm{b}$ and $\mathrm{d}$, the oil/water interface is similar to type A and $\mathrm{C}$, respectively. For the inlet with large orientation angle such as the residual oil blocks in region $\mathrm{c}$, the oil/water interface is similar to type B. Thus, in mixed-wetted rocks, the pore-scale morphology of oil/water interface is controlled by the interaction of contact angle $(\theta)$ and orientation angle $(\beta)$. The results are consistent with the numerical simulation results by Rabbani et al. $[45,46]$. For all 20 residual oil blocks, the outlet is strong water-wetted. It is also found that in mixed-wetted reservoirs, the residual oil is easily formed in the water-wetted and transition-wettability pores.

The capillary pressure and oil/water distribution of type A, B, and C residual oil block in 3D printed sandstone is shown in Fig. 19, Fig. 20, and Fig. 21. It demonstrates that the capillary pressure is a driving force for waterflooding at the water-wetted inlet (such as the type $\mathrm{C}$ residual oil block) and is a resistance of waterflooding at the oil-wetted inlet (such as the type A residual oil block). At the outlet of flow, the capillary pressure is a resistance of waterflooding for each residual oil block and the resistance is always larger than the driving force. Thus, the entire capillary pressure is negative along the flow direction is the essential cause of the formation of residual oil.

\section{Conclusions}

In this paper, we carry out the pore-scale waterflooding experiments on both mixed-wetted natural sandstone and 3D printed sandstone using micro-computed tomography. Based on the obtained images of oil/water distribution, the pore-scale wettability, residual oil pattern and capillary pressure are presented. The influencing factors of the residual oil block are analyzed. The following conclusions can be obtained: 
(1) The pore-scale wettability distribution in the rock is investigated. The contact angles of both the macro oil-wetted natural sandstone and macro mixed-wetted 3D printed sandstone distribute in a wide range with the values both above and below $90^{\circ}$. The macro-scale wettability of the reservoir is the interaction of the heterogeneous pore-scale wettability.

(2) Using the shape factor $(G)$ and Euler number $\left(E_{N}\right)$, the morphology and connectivity of residual oil residual blocks are quantitatively analyzed during water flooding, the volume of network pattern and cluster pattern oil obviously reduces in both two samples, which indicates that the two types of oil blocks contribute to most of the oil recovery. The negative power distribution between the shape factor and the Euler number of residual oil is found, which indicates that good connectivity of pores leads to a complex structure of the residual oil block, e.g. the network pattern and the film pattern. Although the morphology of network pattern residual oil blocks is very complex (small shape factor), they still have great exploitation potential since their excellent connectivity (highly negative Euler number).

(3) In the oil-wetted natural sandstone, there is a micro-fracture caused by the injected water during waterflooding, which increases the permeability of the sample and enhances oil recovery. But the interconnected fractures tend to form the main leakage channels for the breakthrough of injected water, which decreases the sweeping efficiency of small pores in the neighborhood.

(4) For residual oil blocks, the capillary pressure is generally the essential cause of the formation of residual oil. In mixed-wetted reservoirs, the residual oil is easily trapped in the water-wetted and transitionwettability pores.

(5) The morphology of the oil/water interface is mainly controlled by contact angle $(\theta)$ for the strong water-wetted and oil-wetted pores and controlled by the pore geometry for the intermediate-wetted pores. Thus, in mixed wetted rocks, the pore-scale morphology of the oil/water interface is the result of the interaction of contact angle $(\theta)$ and orientation angle $(\beta)$.

\section{Acknowledgments}

We greatly appreciate the financial support of the National Natural Science Foundation of China [Grant No. 51909225]; National Science and Technology Major Project of China [Grant No. 2017ZX05013001002]; and the Open Research Fund of State Key Laboratory of Geomechanics and Geotechnical Engineering, 424 from China Scholarship Council. We also acknowledge the financial support of King Abdullah University of 425 Science and Technology (KAUST) through the grant BAS/1/1351-01 and the support from National Nature 426 Science Foundation of China through the grant No. 51874262. 
Journal of Energy Resources Technology

428

429 Nomenclature

430

$\begin{array}{ll}\theta & \text { contact angle }\left(^{\circ}\right) \\ n_{1} & \text { the normal vector of the oil/water surface } \\ n_{2} & \text { the normal vector of the water/ rock surface } \\ \Phi & \text { porosity }(\%) \\ V_{b} & \text { total volume of the sample }\left(\mu \mathrm{m}^{3}\right) \\ V_{p} & \text { the volume of pore }\left(\mu \mathrm{m}^{3}\right) \\ V_{s} & \text { the volume of rock grain }\left(\mu \mathrm{m}^{3}\right) \\ b_{N} & \text { the number of isolated components } \\ b_{o} & \text { the volume of the given oil block }\left(\mu \mathrm{m}^{3}\right) \\ V_{o i} & \text { water saturation }(\%) \\ S_{w} & \text { the volume of oil }\left(\mu \mathrm{m}^{3}\right) \\ V_{o} & \text { the volume of water }\left(\mu \mathrm{m}^{3}\right) \\ & \end{array}$


Journal of Energy Resources Technology

$\begin{array}{ll}b_{2} & \text { the number of voids } \\ k & \text { mean curvature }(1 / \mu \mathrm{m}) \\ k_{1} & \text { the first principal curvature } \\ k_{2} & \text { the second principal curvature } \\ P_{c} & \text { capillary pressure }(\mathrm{kPa}) \\ \sigma & \text { surface tension coefficient }(\mathrm{N} / \mathrm{m}) \\ \beta & \text { orientation angle }\left(^{\circ}\right)\end{array}$


Journal of Energy Resources Technology

433

434

435

436

437

438

439

440

441

442

443

444

445

446

447

448

449

450

451

452

453

454

455

456

457

458

459

460

461

462

463

464

465

466

467

468

469

470

471

472

473

\section{References}

[1] Song, R., Cui, M., \& Liu, J., 2017. Single and multiple objective optimization of a natural gas liquefaction process. Energy, 124, 19-28. DOI:10.1016/j.energy.2017.02.073

[2] Hao, J. S., Mohammadkhani, S., Shahverdi, H., Esfahany, M. N., and Shapiro, A., 2019, "Mechanisms of smart waterflooding in carbonate oil reservoirs-A review," J. Petrol. Sci. Eng., 179, pp. 276-291.DOI: 10.1016/j.petrol.2019.04.049

[3] Yang, R. F., Zhang J. Q., Chen, H., Jiang, R. Z., Sun, Z., Rui, Z. H., 2019, “The injectivity variation prediction model for water flooding oilfields sustainable development," Energy, DOI: 10.1016/j.energy.2019.116317

[4] Guo, C. H., Wang, X., Wang, H., He, S., Liu, H., and Zhu, P., 2018, "Effect of pore structure on displacement efficiency and oil-cluster morphology by using micro computed tomography ( $\mu \mathrm{ct}$ ) technique," Fuel, 230, pp. 430-439. DOI: 10.1016/j.fuel.2018.05.058

[5] Gu, X. y., Pu, C. S., Khan, N., Wu, F. P., Huang, F. F., and Xu, H. X., 2019, “The visual and quantitative study of remaining oil micro-occurrence caused by spontaneous imbibition in extra-low permeability sandstone using computed tomography," Fuel, 237, pp. 152-162. DOI: 10.1016 / j.fuel. 2018. 09.014

[6] Jamaloei, B. Y., Asghari, K., Kharrat, R., and Ahmadloo, F., 2010, "Pore-scale two-phase filtration in imbibition process through porous media at high- and low-interfacial tension flow conditions," J. Petrol. Sci. and Eng., 72(3-4), pp. 251-269. DOI: 10.1016/j.petrol.2010.03.026

[7] Song, W., and Kovscek, A. R., 2016, "Direct visualization of pore-scale fines migration and formation damage during low-salinity waterflooding,” J. Nat. Gas Sci. Eng., 34, pp.1276-1283. DOI: 10.1016 / j.jngse.2016.07.055

[8] Di, Q. F., Zhang, J. N., Hua, S., Chen, H. J, and Gu, C. Y., 2017, "Visualization experiments on polymerweak gel profile control and displacement by nmr technique," Petrol. Explor. Dev., 44(2), pp. 294-298. DOI: 10.1016/s1876-3804(17)30033-2

[9] Romero-Zeron, L. B., Li, L., Ongsurakul, S., and Balcom, B., 2009, "Visualization of waterflooding through unconsolidated porous media using magnetic resonance imaging," Petrol. Sci. Technol., 27(17), pp. 1993-2009. DOI: 10.1080/10916460802611267

[10] Cheng, Y. C., Di, Q. F., Gu, C. Y.,Ye, F., Hua, S., and Yang, P. Q., 2015, "Visualization study on fluid distribution and end effects in core flow experiments with low-field mri method," J. Hydrodyn., 27(2), pp.187-194. DOI: 10.1016/S1001-6058(15)60471-1

[11] Krummel, A. T., Datta, S. S., Münster, S., and Weitz, D. A., 2013, "Visualizing multiphase flow and trapped fluid configurations in a model three - dimensional porous medium,” Aiche J., 59(3), pp. 1022-1029. DOI: 10.1002/aic.14005

[12] Li, Y. Q., Yang, Y., Sun, X. D., Yang, D., Zhang, N., Yang, H. J., Guo, H., and Zheng, J., 2014, “The application of laser confocal method in microscopic oil analysis," J. Petrol. Sci. Eng., 120, pp. 52-60. DOI: 10.1016/j.petrol.2014.04.005

[13] Scanziani, A., Singh, K., Blunt, M. J., and Guadagnini, A., 2017, “Automatic method for estimation of, in situ, effective contact angle from X-ray micro tomography images of two-phase flow in porous media," J. Colloid Interf. Sci., 496, pp. 51-59. DOI: 10.1016/j.jcis.2017.02.005 
Journal of Energy Resources Technology

474 [14] Wang, Y., Song, R., Liu, J. J., Cui, M. M., and Ranjith, P. G., 2019, "Pore scale investigation on scaling475 up micro-macro capillary number and wettability on trapping and mobilization of residual fluid," J. Contam.

476 Hydrol., 225, pp. 103499. DOI: 10.1016/j.jconhyd.2019.103499

477 [15] Song, R., Wang, Y., Liu, J. J., Cui, M. M., and Lei, Y., 2019, “Comparative analysis on pore--scale 478 permeability prediction on micro-CT images of rock using numerical and empirical approaches," Energy Sci.

479 Eng., DOI: 10.1002/ese3.465

480 [16]Zhu, H. L., Wang, S. F., Yin, G. J., Chen, Q., Xu, F. L., Peng, W., 2018, "Study of the numerical 481 simulation of tight sandstone gas molecular diffusion based on digital core technology," Petrol. Sci., 15(1), pp. 68-76. DOI: 10.1007/s12182-017-0210-1

[17] Andrew, M., Bijeljic, B., and Blunt, M. J., 2013, "Pore-scale imaging of geological carbon dioxide storage under in situ conditions,” Geophys. Res. Lett., 40(15), pp. 3915-3918. DOI: 10.1002/grl.50771

[18] Wang, D. G., Hu, Y. L., and Sun, J. J., 2015, "X-ray MCT based numerical analysis of residual oil porescale characteristics under various displacing systems," J. Petrol. Sci. Eng., 135, pp. 168-176. DOI: 10.1016/j.petrol.2015.09.015 [19] Gu, X. Y., Pu, C. S., Huang, H., Khan, N., Liu, J., He, Y. L., Jing, C., Huang, F. F., Qi, A., 2018, “The Visual and Quantitative Study of the Microoccurrence of Irreducible Water at the Pore and Throat System in a Low-Permeability Sandstone Reservoir by Using Microcomputerized Tomography," Geofluids, 2018, DOI: $10.1155 / 2018 / 6062475$

[20] Scanziani, A., Singh, K., Bultreys, T. Bijeljic, B., Blunt, M. J., 2018, "In situ characterization of immiscible three-phase flow at the pore scale for a water-wet carbonate rock," Adv. Water Resour., 121, pp. 446-455. DOI: 10.1016/j.advwatres.2018.09.010 [21] Li, J. J., Jiang, H. Q., Wang, C., Zhao, Y. Y., Gao, Y. J., Pei, Y. L., Wang, C. C., and Dong, H., 2017, "Pore-scale investigation of microscopic remaining oil variation characteristics in water-wet sandstone using CT scanning,” J. Nat. Gas Sci. Eng., 48, pp. 36-45. DOI: 10.1016/j.jngse.2017.04.003 [22] Li, J. J., Gao, Y. J., Jiang, H. Q., Liu, Y., Dong, H., 2018, "Pore-scale imaging of the oil cluster dynamic during drainage and imbibition using in situ X-ray microtomography," Geofluids, 2018. DOI: $10.1155 / 2018 / 7679607$

[23] Yang, Y. F., Yang, H. Y., Tao, L., Yao, J., Wang, W. D., Zhang, K., and Luquot, L., 2019, “Microscopic Determination of Remaining Oil Distribution in Sandstones With Different Permeability Scales Using Computed Tomography Scanning," J. Energy Resour. Technol., 141(9), pp. 092903. DOI: $10.1115 / 1.4043131$

[24] Akai, T., Alhammadi, A. M., Blunt, M. J., and Bijeljic, B., 2019, "Modeling Oil Recovery in MixedWet Rocks: Pore-Scale Comparison Between Experiment and Simulation,” Transport Porous Med., 127(2), pp. 393-414. DOI: 10.1007/s11242-018-1198-8

[25] Mohammed, M., and Babadagli, T., 2015, "Wettability alteration: A comprehensive review of materials/methods and testing the selected ones on heavy-oil containing oil-wet systems," Adv. Colloid Interfac. Sci., 220, pp. 54-77. DOI: 10.1016/j.cis.2015.02.006 [26]Bartels, W, B., Rücker, M., Berg, S., Mahani, H.. Georgiadis, A., Fadili, A., Brussee, N., Coorn, A., Linde, H., Hinz, C., Jacob, A., Wagner, C., Henkel, S., Enzmann, F., Bonnin, A., Stampanoni, M., Ott, H., Blunt, M., Hassanizadeh, S.M., 2017, "Fast X-ray micro-CT study of the impact of brine salinity on the porescale fluid distribution during waterflooding," Petrophysics, 58(01). PP. 36-47. DOI: SPWLA-2017-v58n1a4 
Journal of Energy Resources Technology

515 [27] Blunt, M. J., 2017, Multiphase flow in permeable media: A pore-scale perspective, Cambridge University Press, London, UK, ISBN-13: 978-1107093461 [28] Santini, M., Guilizzoni, M., and Fest-Santini. S., 2013, "X-ray computed microtomography for drop shape analysis and contact angle measurement," J. colloid interf. Sci., 409, pp. 204-210. DOI: 10.1016/j.jcis.2013.06.036

[29] Goda, H. M., Behrenbruch, P., 2011, Wettability quantification-Prediction of wettability for Australian formations," International Petroleum Technology Conference, Bangkok, Thailand, November 15-17, 2011. DOI: 10.2523/IPTC-15230-MS

[30] Donaldson, E. C., Thomas, R. D., and Lorenz, P. B., 1969, "Wettability determination and its effect on recovery efficiency,” SPE J., 9(01), pp. 13-20. DOI: 10.2118/2338-PA [31] AlRatrout, A., Raeini, A. Q., Bijeljic, B., and Blunt, M. J., 2017, “Automatic measurement of contact angle in pore-space images,” Adv. Water Resour., 109, pp. 158-169. DOI: 10.1016/j.advwatres. 2017. 07. 018

[32] Alhammadi, A. M., Alratrout, A., Singh, K., Bijeljic, B., and Blunt, M. J., 2017, "In situ characterization of mixed-wettability in a reservoir rock at subsurface conditions," Sci. Rep., 7(1), pp. 10753. DOI: 10.1038/s41598-017-10992-w [33] Alratrout, A., Blunt, M. J., and Bijeljic, B., 2018, "Spatial Correlation of Contact Angle and Curvature in Pore-Space Images,” Water Resour. Res., 54(9), pp. 6133-6152. DOI: 10.1029/2017WR022124 [34] AlRatrout, A., Blunt, M. J., and Bijeljic, B., 2018, "Wettability in complex porous materials, the mixedwet state, and its relationship to surface roughness," P. Natl. Acad. Sci. USA, 115 (36), pp. 8901-8906. DOI: 10.1073/pnas.1803734115

[35] Akai, T., Alhammadi, A. M., Blunt, M. J., and Bijeljic, B., 2019, "Modeling Oil Recovery in MixedWet Rocks: Pore-Scale Comparison Between Experiment and Simulation,” Transport Porous Med., 127(2), pp. 393-414. DOI: 10.1007/s11242-018-1198-8

[36] Armstrong, R. T., Porter, M. L., and Wildenschild, D., 2012, "Linking pore-scale interfacial curvature to column-scale capillary pressure," Adv. Water Resour., 46(9), pp. 55-62. DOI: 10.1016/j.advwatres. 2012.05.009

542 [37] Andrew, M., Bijeljic, B., and Blunt, M. J., 2014, "Pore by pore capillary pressure measurements using 543 X-ray microtomography at reservoir conditions: Curvature, snap-off, and remobilization of residual CO2," 544 Water Resour. Res., 50(11), pp. 8760-8774. DOI: 10.1002/2014WR015970

545 [38] Garing, C., De Chalendar, J. A., Voltolini, M., Ajo-Franklin, J. B., and Benson, S. M., 2017, "Pore-scale 546 capillary pressure analysis using multi-scale X-ray micromotography,” Adv. Water Resour., 104, pp. 223547 241. DOI: 10.1016/j.advwatres.2017.04.006

548 [39] Lin, Q. Y., Bijeljic, B., Pini, R., Blunt, M. J., and Krevor, S., 2018, "Imaging and Measurement of Pore549 Scale Interfacial Curvature to Determine Capillary Pressure Simultaneously With Relative Permeability," 550 Water Resour. Res., 54(9): 7046-7060. DOI: 10.1029/2018WR023214

551 [40] Buades, A., Coll, B., and Morel, J. M., "Nonlocal Image and Movie Denoising," Int. J.1 Comput. Vision, 552 76(2), pp. 123-139. DOI: 10.1007/s11263-007-0052-1

553 [41] Jones, A. C., Arns, C. H., Sheppard, A. P., Hutmacher, D. W., Milthorpe, B. K., and Knackstedt, M. A., 5542007 , “Assessment of bone ingrowth into porous biomaterials using MCT," Biomaterials, 28(15), pp. 2491555 2504. DOI: 10.1016/j.biomaterials.2007.01.046 
556 [42] Schlüter, S., Sheppard, A., Brown, K., and Wildenschild, D., 2014, "Image processing of multiphase 557 images obtained via x-ray microtomography: a review," Water Resour. Res., 50(4), pp. 3615-3639. DOI: 558 10.1002/2014WR015256

559 [43] Prodanović, M., Lindquist, W. B., Seright, R. S., 2007, "3D image-based characterization of fluid 560 displacement in a Berea core," Adv. Water Resour., 30(2), pp. 214-226. DOI: 10.1016/j.advwatres. 2005. $561 \quad 05.015$

562 [44] Andersson, L., Herring, A., Schlueter, S., and Wildenschild, D., 2018, "Defining a novel pore-body to 563 pore-throat "Morphological Aspect Ratio" that scales with residual non-wetting phase capillary trapping in 564 porous media,” Adv. Water Resour., 122, pp. 251-262. DOI: 10.1016/j.advwatres.2018.10.009

565 [45] Rabbani, H. S., Zhao, B. Z., Juanes, R., and Shokri, N., 2018, "Pore geometry control of apparent wetting 566 in porous media," Sci. rep. UK, 8(1): pp. 15729. DOI: 10.1038/s41598-018-34146-8

567 [46] Rabbani, H. S., Joekar-Niasar, V., and Shokri, N., 2016, "Effects of intermediate wettability on entry 568 capillary pressure in angular pores,” J. Colloid Interf. Sci.,473, pp. 34-43. DOI: 10.1016/j.jcis.2016.03.053

569

570 


\begin{tabular}{|c|c|}
\hline Fig. 1 & $\begin{array}{l}\text { The Contact angle measured by the sessile drop method. (a1) (a2) are the results of natural } \\
\text { sandstone; (b1) } \sim(\mathrm{b} 2) \text { are the results of } 3 \mathrm{D} \text { printed sandstone }\end{array}$ \\
\hline Fig. 2 & $\begin{array}{l}\text { The pore diameter distribution of the selected samples. (a)The result for the natural } \\
\text { sandstone; (b)The result for the } 3 \mathrm{D} \text { printed sandstone }\end{array}$ \\
\hline Fig. 3 & $\begin{array}{l}\text { Schematic diagram of the experimental system. 1-water; 2-pump for displacement; 3- } \\
\text { hydraulic oil; 4-Transfer vessel for water; 5-Transfer vessel for oil; 6- pump for confining } \\
\text { pressure; 7-core holder; 8-X-ray source; 9-pressure transducer; 10-the measurement } \\
\text { system; 11-Xradia Microxct-400 }\end{array}$ \\
\hline Fig. 4 & $\begin{array}{l}\text { Experimental apparatus. (a) X-ray micro-computerized tomography scanner; (b) } \\
\text { Displacement experiment system; (c) The internal structure of core holder }\end{array}$ \\
\hline Fig. 5 & $\begin{array}{l}\text { Image processing. (a1) Image before nonlocal-means filtering for natural sandstone, in } \\
\text { which the black phase is water, gray phase is rock grain and intermediate phase is oil; (a2) } \\
\text { Image after nonlocal-means filtering for natural sandstone; (a3) The segmented image } \\
\text { after watershed segmentation for natural sandstone, in which water is the green phase, oil } \\
\text { is the yellow phase and rock grain is gray phase; (b1) (b3) are the same image processing } \\
\text { for } 3 \mathrm{D} \text { printed sandstone }\end{array}$ \\
\hline Fig. 6 & $\begin{array}{l}\text { The workflow of capillary pressure calculation. (a) The segmented image of natural } \\
\text { sandstone after waterflooding; (b) The two dimensional slice of the selected network } \\
\text { pattern residual oil block; (c) The selected network pattern residual oil block; (d) The } \\
\text { smoothed oil/water surface;(e) The curvature distribution of the selected residual oil block; } \\
\text { (f) The capillary pressure distribution of the selected residual oil block. In which, oil is } \\
\text { transparent blue. The brief workflow of capillary pressure calculation is: First, based on } \\
\text { the segmented images, the oil/water interface is extracted. Second, a smoothed surface is } \\
\text { generated at the oil/water interface by using the generalized marching cubes algorithm. } \\
\text { Third, the two principal curvatures are found by approximating the surface locally as a } \\
\text { quadratic form. Fourth, the mean curvature of the oil/water surface is obtained by the } \\
\text { average of the two principal curvatures. Fifth, the capillary pressure distribution can be } \\
\text { obtained from the mean curvature using the Yang-Laplace equation. }\end{array}$ \\
\hline Fig. 7 & $\begin{array}{l}\text { The histogram of in-situ contact angles. (a) The results for natural sandstone; (b) The } \\
\text { results for } 3 \mathrm{D} \text { printed sandstone }\end{array}$ \\
\hline Fig. 8 & $\begin{array}{l}\text { Classification of oil block patterns before waterflooding. (a1) Isolated pattern in natural } \\
\text { sandstone; (a2) Cluster pattern in natural sandstone; (a3) Network pattern in natural } \\
\text { sandstone; (a4) Film pattern in natural sandstone; (b1) (b3) are the results for 3D printed } \\
\text { sandstone. In 3D printed sandstone, there is no film pattern oil block }\end{array}$ \\
\hline Fig. 9 & $\begin{array}{l}\text { Classification of residual oil block patterns after waterflooding. (a1) Isolated pattern in } \\
\text { natural sandstone; (a2) Cluster pattern in natural sandstone; (a3) Network pattern in natural }\end{array}$ \\
\hline
\end{tabular}




\begin{tabular}{|c|c|}
\hline & $\begin{array}{l}\text { sandstone; (a4) Film pattern in natural sandstone; (b1) (b3) are the results for 3D printed } \\
\text { sandstone. In 3D printed sandstone, there is no film pattern residual oil block }\end{array}$ \\
\hline Fig. 10 & $\begin{array}{l}\text { The oil saturation of all types of oil blocks during waterflooding. (a) The results for natural } \\
\text { sandstone; (b) The results for 3D printed sandstone }\end{array}$ \\
\hline Fig. 11 & $\begin{array}{l}\text { Statistical results of shape factor and Euler Number. (a) The results for natural sandstone; } \\
\text { (b) The results for } 3 \mathrm{D} \text { printed sandstone }\end{array}$ \\
\hline Fig. 12 & $\begin{array}{l}\text { The fracture Extracting. (a1) The original segmentation image before waterflooding; (a2) } \\
\text { The oil/water distribution in the fracture before waterflooding; (a3) The distribution of } \\
\text { water in the fracture before waterflooding; (b1) (b3) are the results after waterflooding }\end{array}$ \\
\hline Fig. 13 & $\begin{array}{l}\text { The variation of the morphology of film pattern oil in the fracture. (a) The film pattern oil } \\
\text { in the fracture before waterflooding; (b) The film pattern residual oil in the fracture after } \\
\text { waterflooding }\end{array}$ \\
\hline Fig. 14 & $\begin{array}{l}\text { The cross-section of the fracture along the flow direction during waterflooding. (a) The } \\
\text { cross section of fracture before waterflooding; (b) The cross-section of fracture after } \\
\text { waterflooding. In which, A1 and A2 directive the no sweeping area, B1 and B } 2 \text { directive } \\
\text { the expansion area of the fracture }\end{array}$ \\
\hline Fig. 15 & $\begin{array}{l}\text { The capillary pressure distribution of residual oil blocks. (a) The capillary pressure } \\
\text { distribution of network pattern residual oil blocks in natural sandstone; (b) The capillary } \\
\text { pressure distribution of film pattern residual oil blocks in natural sandstone; (c) The } \\
\text { capillary pressure distribution of network pattern residual oil blocks in 3D printed } \\
\text { sandstone }\end{array}$ \\
\hline Fig. 16 & $\begin{array}{l}\text { The schematic diagram of residual oil in the narrow throat in the natural sandstone. (a)The } \\
\text { capillary pressure distribution in the narrow throat. It is found that the capillary pressure } \\
\text { is larger in the narrow throat than the value in its neighboring large pores. In which, the } \\
\text { oil surface is transparent blue; (b) The oil/water distribution in the narrow throat }\end{array}$ \\
\hline Fig. 17 & $\begin{array}{l}\text { The schematic diagram of residual oil in the dead-end pore in the natural sandstone. (a) } \\
\text { The capillary pressure distribution in the dead-end pore. It is found that the capillary } \\
\text { pressure in the dead-end pore is larger than the value in its neighboring large pore. In } \\
\text { which, the oil surface is transparent blue; (b) The oil/water distribution in the dead-end } \\
\text { pore }\end{array}$ \\
\hline Fig. 18 & $\begin{array}{l}\text { The statistics of the contact angle }(\theta) \text { and orientation angle }(\beta) \text { of the inlet. There are three } \\
\text { types of morphology of oil/water interface, which are expressed as schematic } \\
\text { representation } \mathrm{A}, \mathrm{B} \text {, and } \mathrm{C} \text {, separately. In the schematic representations, the oil is red and } \\
\text { the water is blue. The selected } 20 \text { residual oil blocks mainly distribute in } 5 \text { regions such as } \\
\mathrm{a}, \mathrm{b}, \mathrm{c}, \mathrm{d} \text {, and } \mathrm{e}\end{array}$ \\
\hline Fig. 19 & $\begin{array}{l}\text { The capillary pressure and oil/water distribution of the type A residual oil block. In which, } \\
\text { the surfaces of oil and water are transparent blue and transparent green, respectively }\end{array}$ \\
\hline Fig. 20 & $\begin{array}{l}\text { The capillary pressure and oil/water distribution of the type B residual oil block. In which, } \\
\text { the surfaces of oil and water are transparent blue and transparent green, respectively }\end{array}$ \\
\hline
\end{tabular}


Journal of Energy Resources Technology

Fig. 21

The capillary pressure and oil/water distribution of the type $\mathrm{C}$ residual oil block. In which, the surfaces of oil and water are transparent blue and transparent green, respectively

574

575 
Journal of Energy Resources Technology

576

577

Table Caption List

578

\begin{tabular}{|l|l|}
\hline Table 1 & The physical properties of the two samples \\
\hline Table 2 & The composition of brine \\
\hline Table 3 & Classification of residual oil block pattern \\
\hline Table 4 & The percentages of water-wetted and oil-wetted part \\
\hline Table 5 & The oil saturation and recovery \\
\hline Table 6 & The volume of oil, water, and oil recovery in the fracture \\
\hline
\end{tabular}

579

580 
Journal of Energy Resources Technology

581

582

583

584

585

586
Information Regarding Figures and Tables

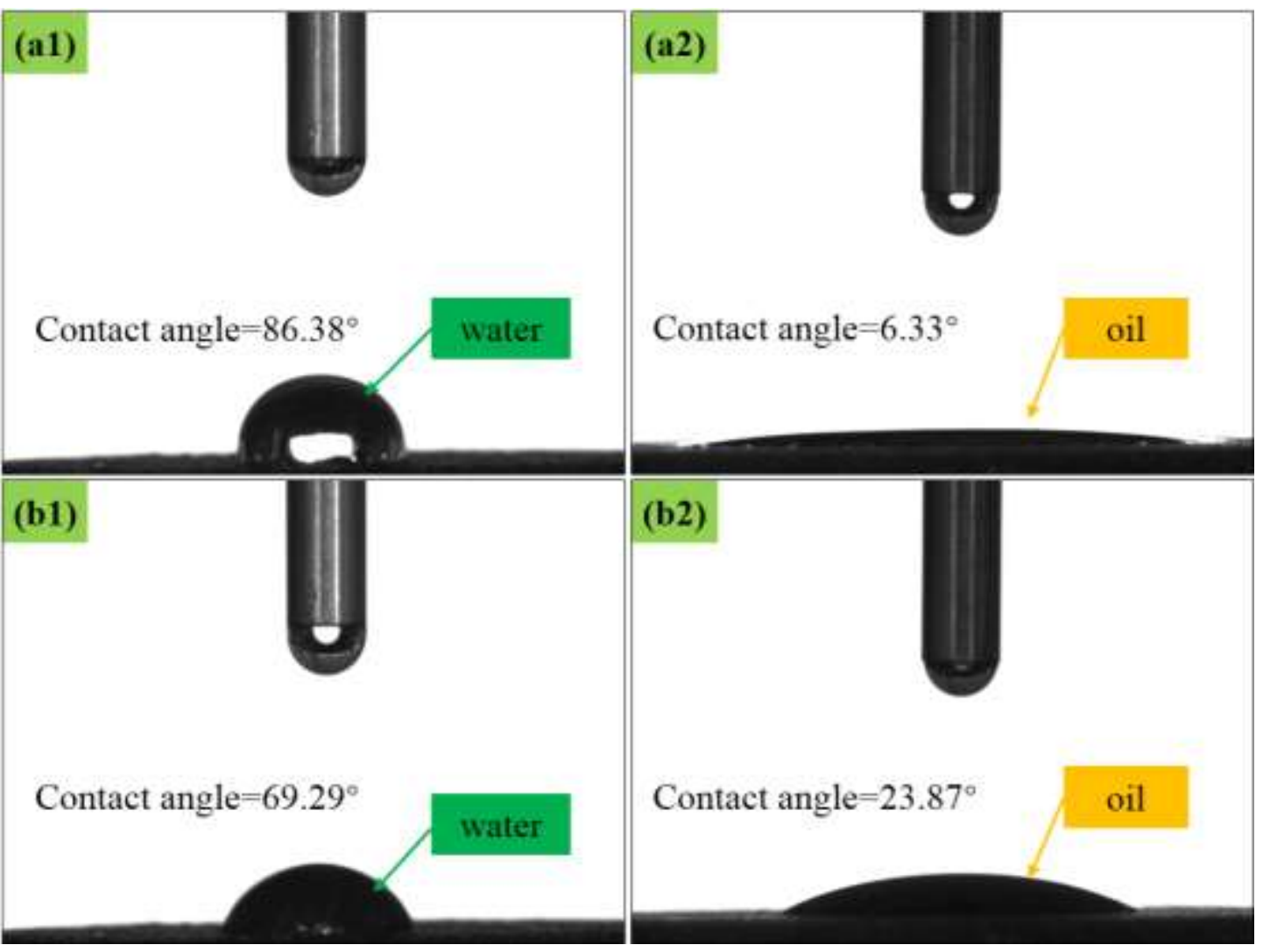

Fig. 1 
Journal of Energy Resources Technology
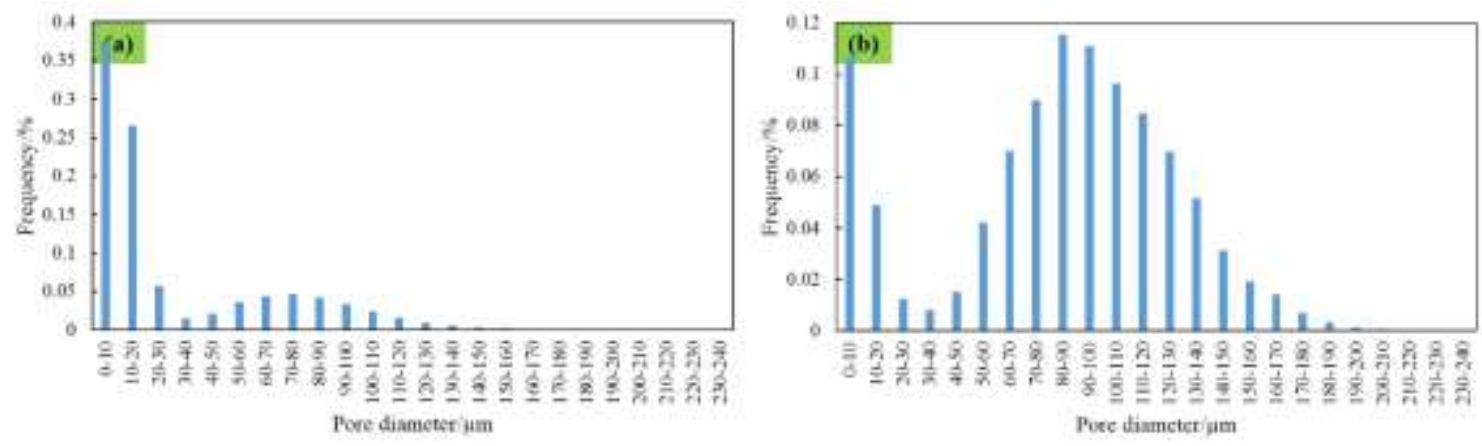

588

Fig. 2

589 
Journal of Energy Resources Technology

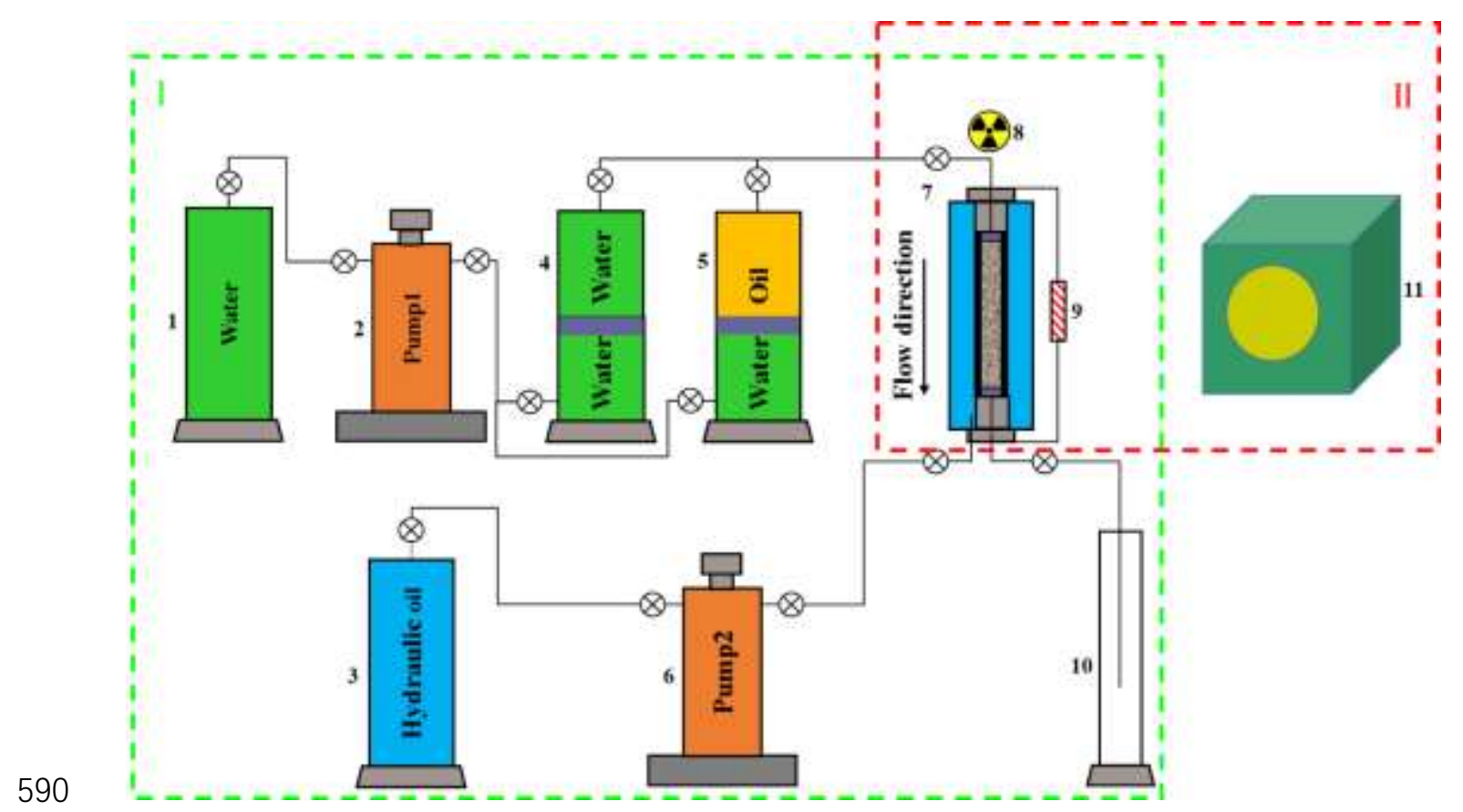

591

Fig. 3

592 


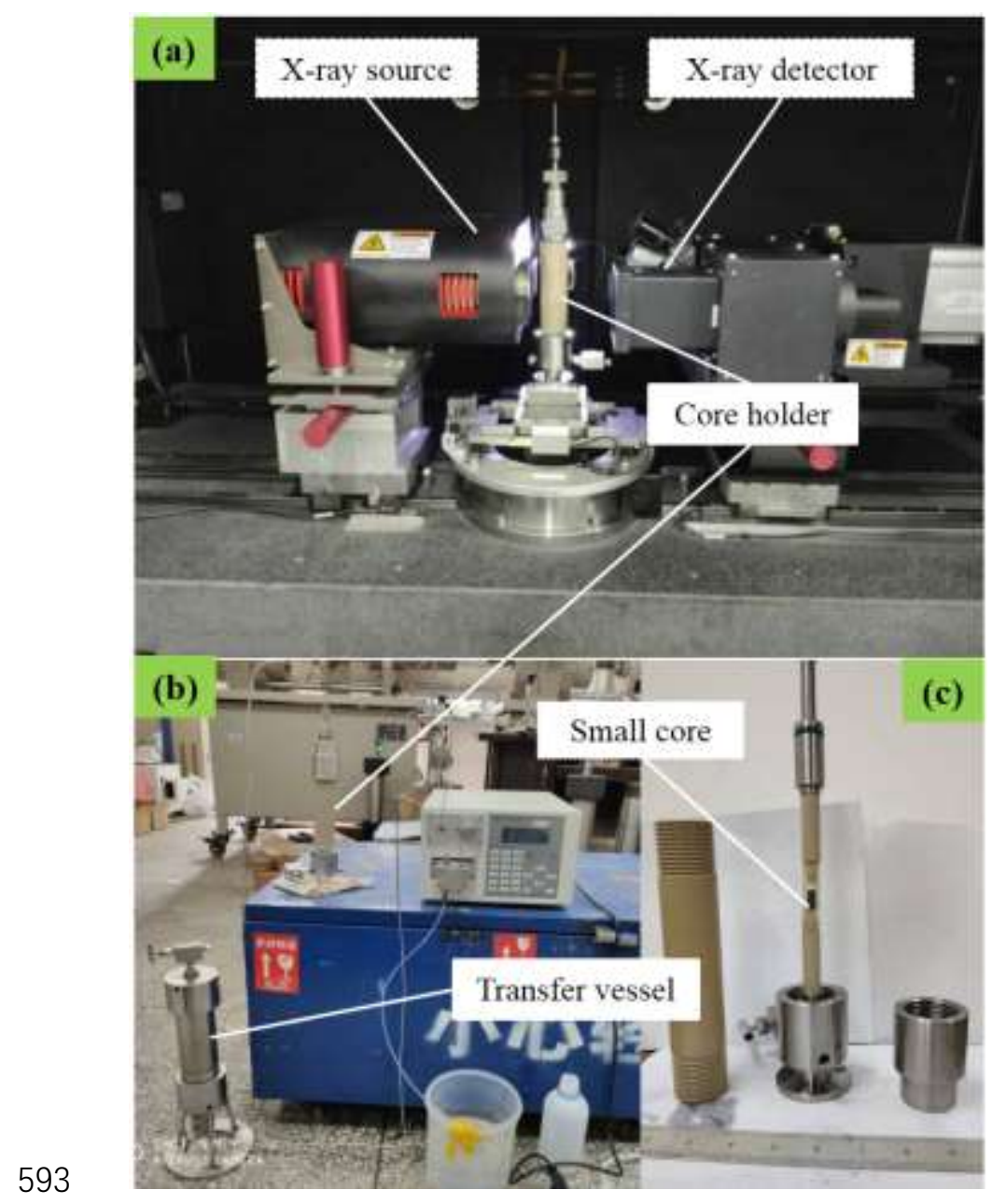

594 Fig. 4

595 
Journal of Energy Resources Technology

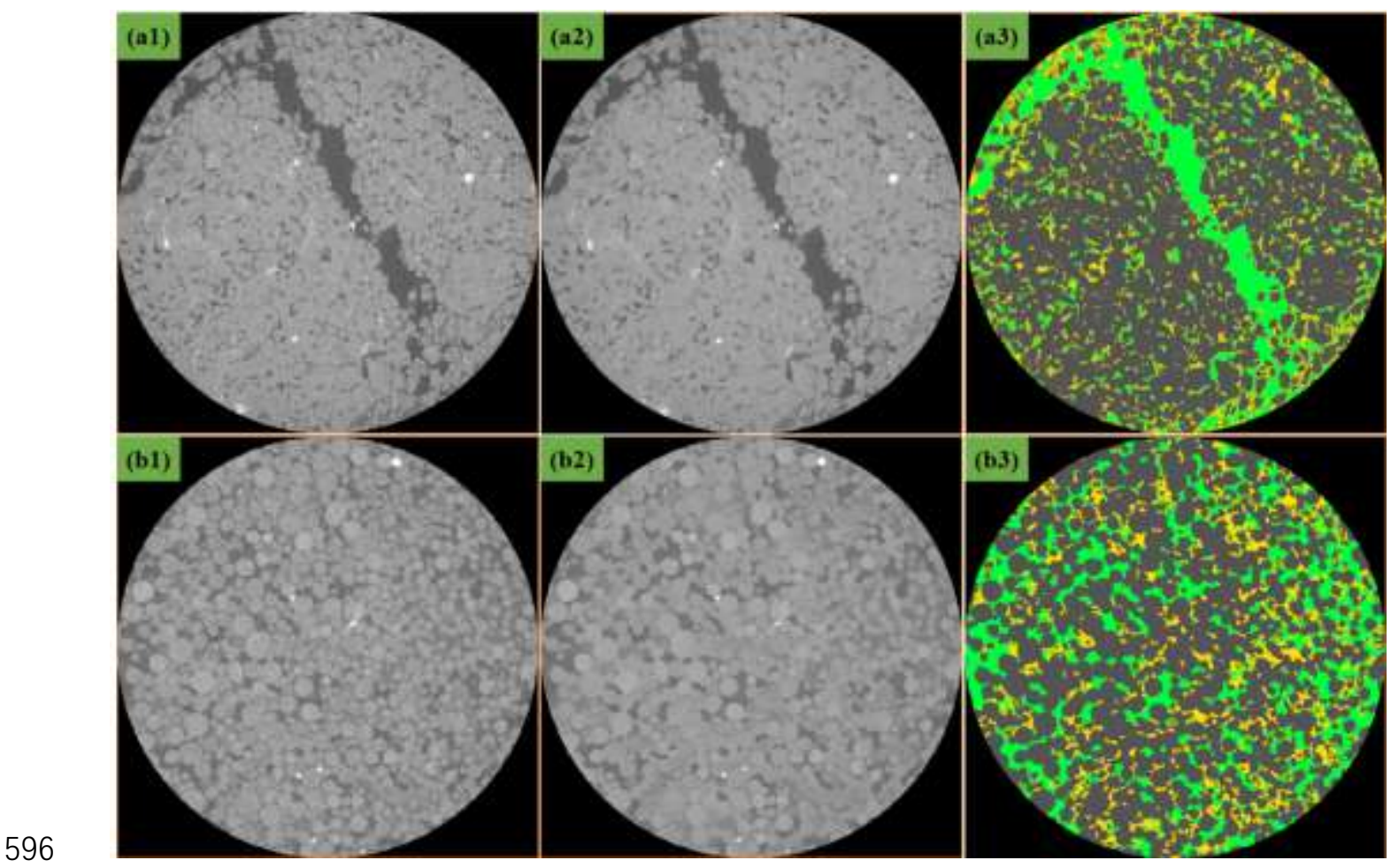

597

Fig. 5

598 


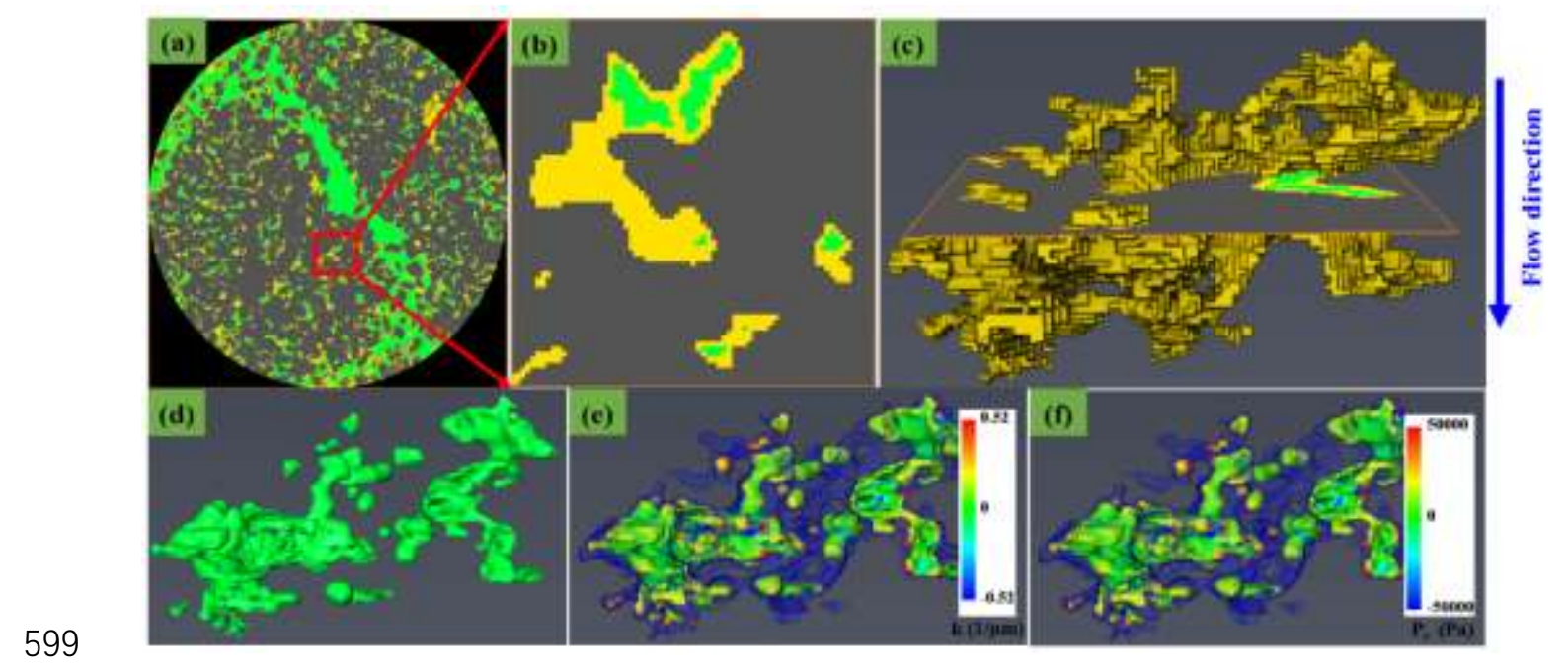

$600 \quad$ Fig. 6

601 
Journal of Energy Resources Technology

602

603

604
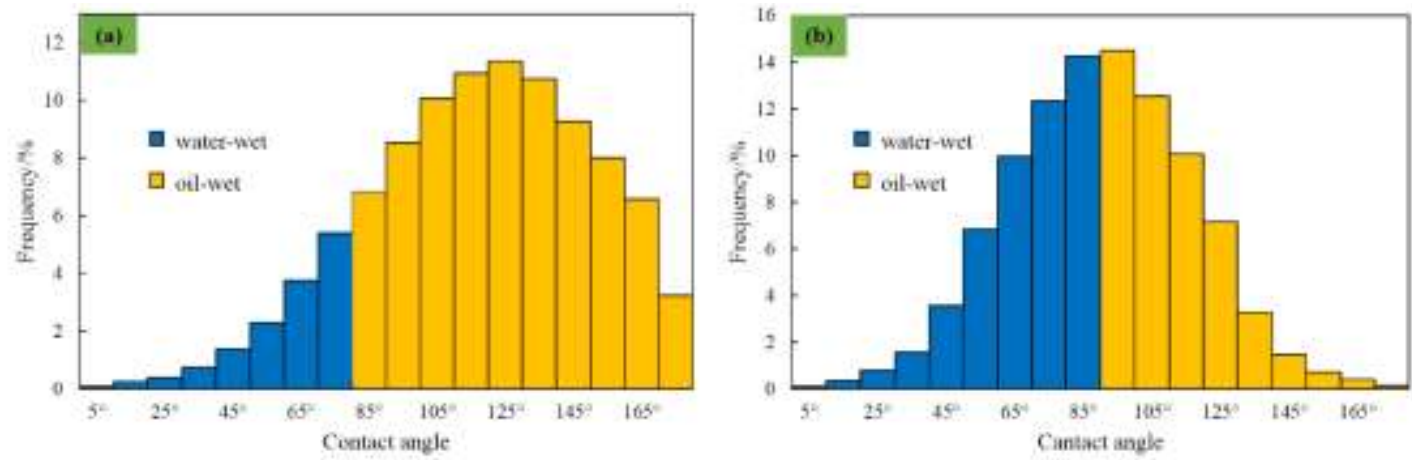

Fig. 7

1g. 7 
Journal of Energy Resources Technology

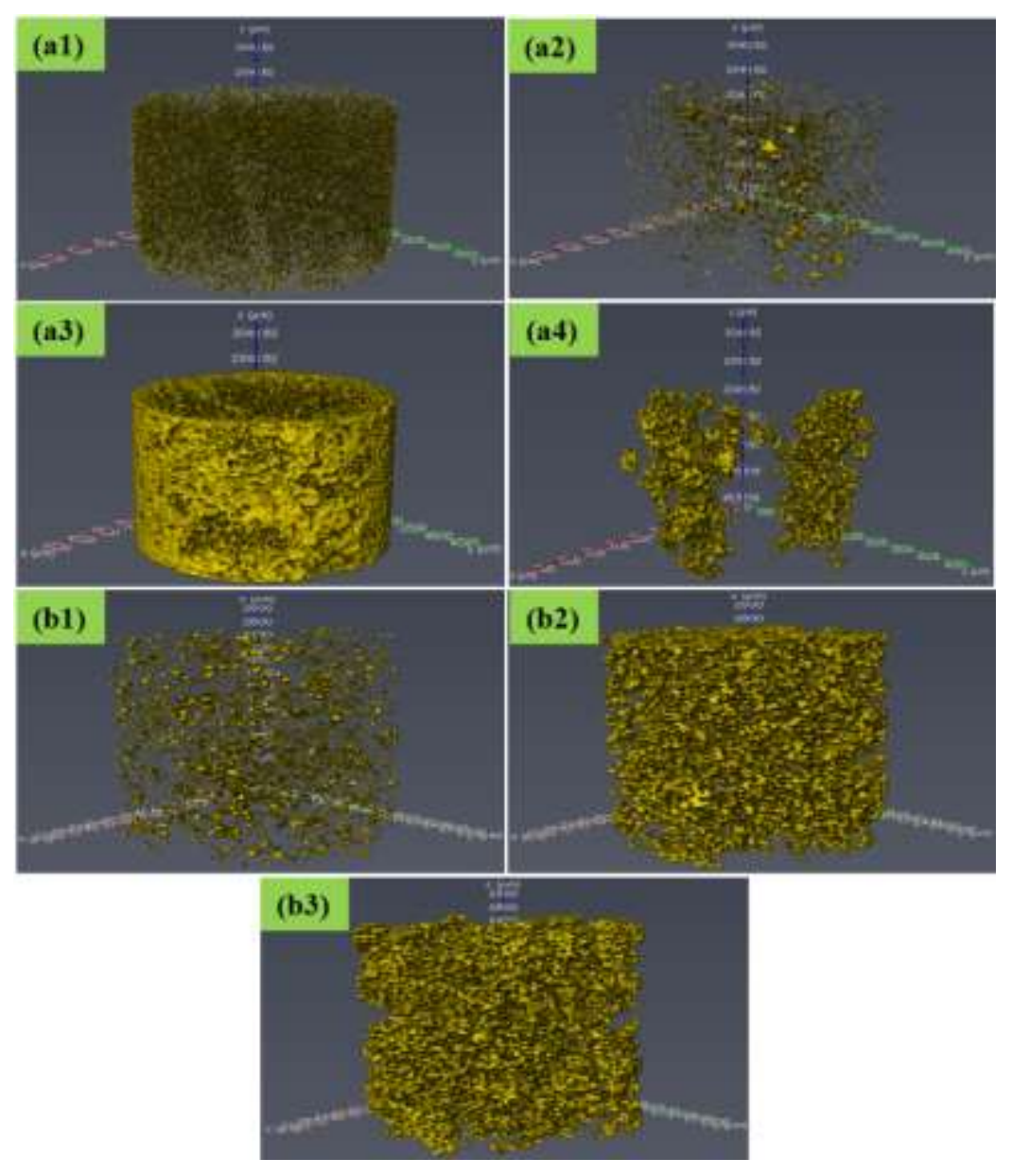

605

Fig. 8

607

608 
Journal of Energy Resources Technology

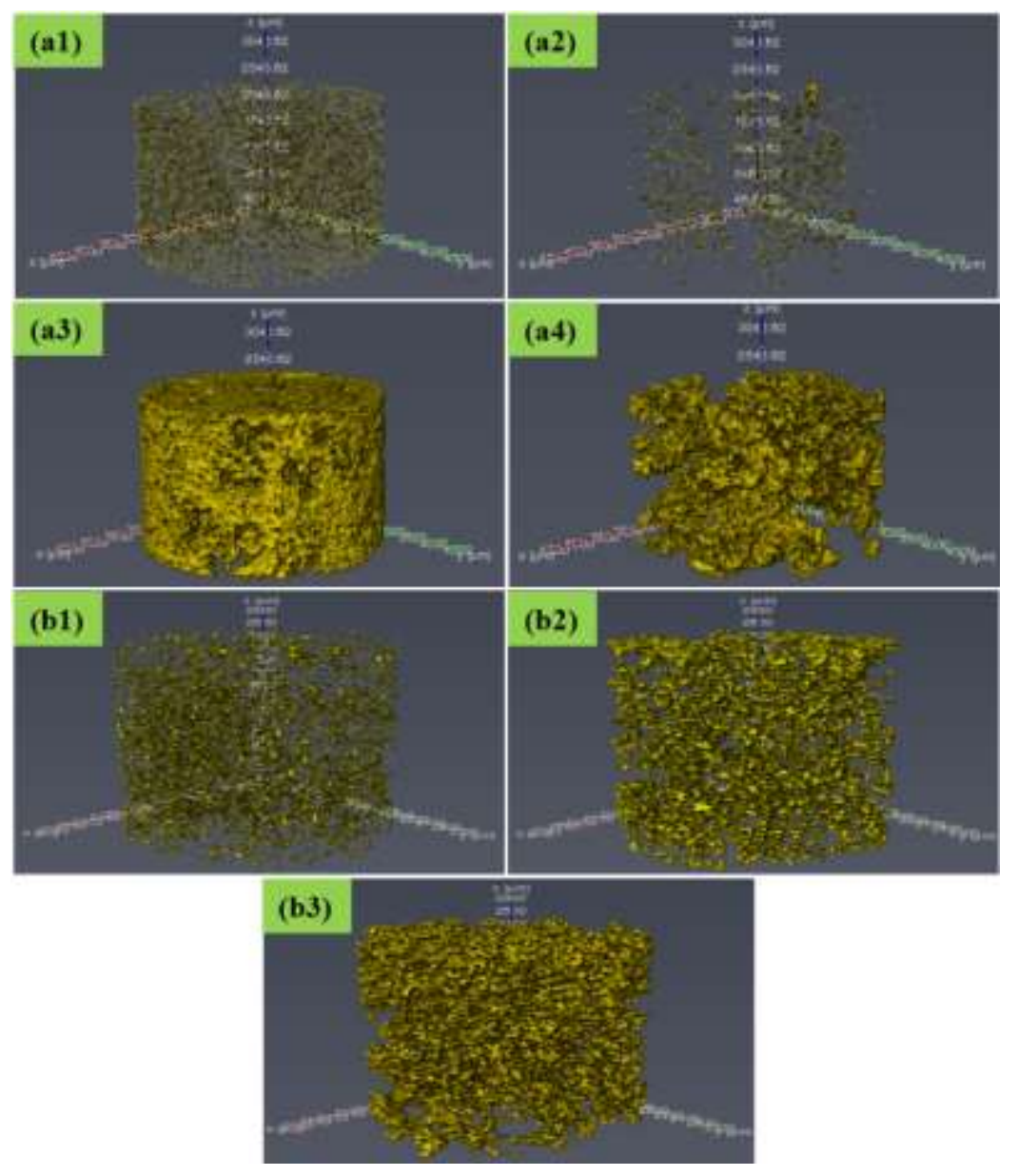

609

Fig. 9

611 
Journal of Energy Resources Technology

612

613

614
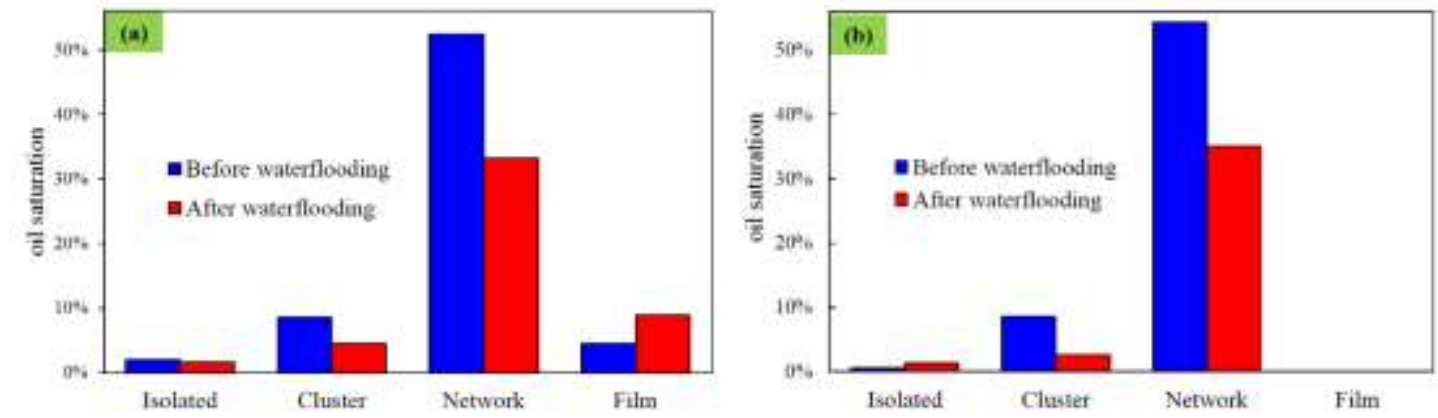

Fig. 10 

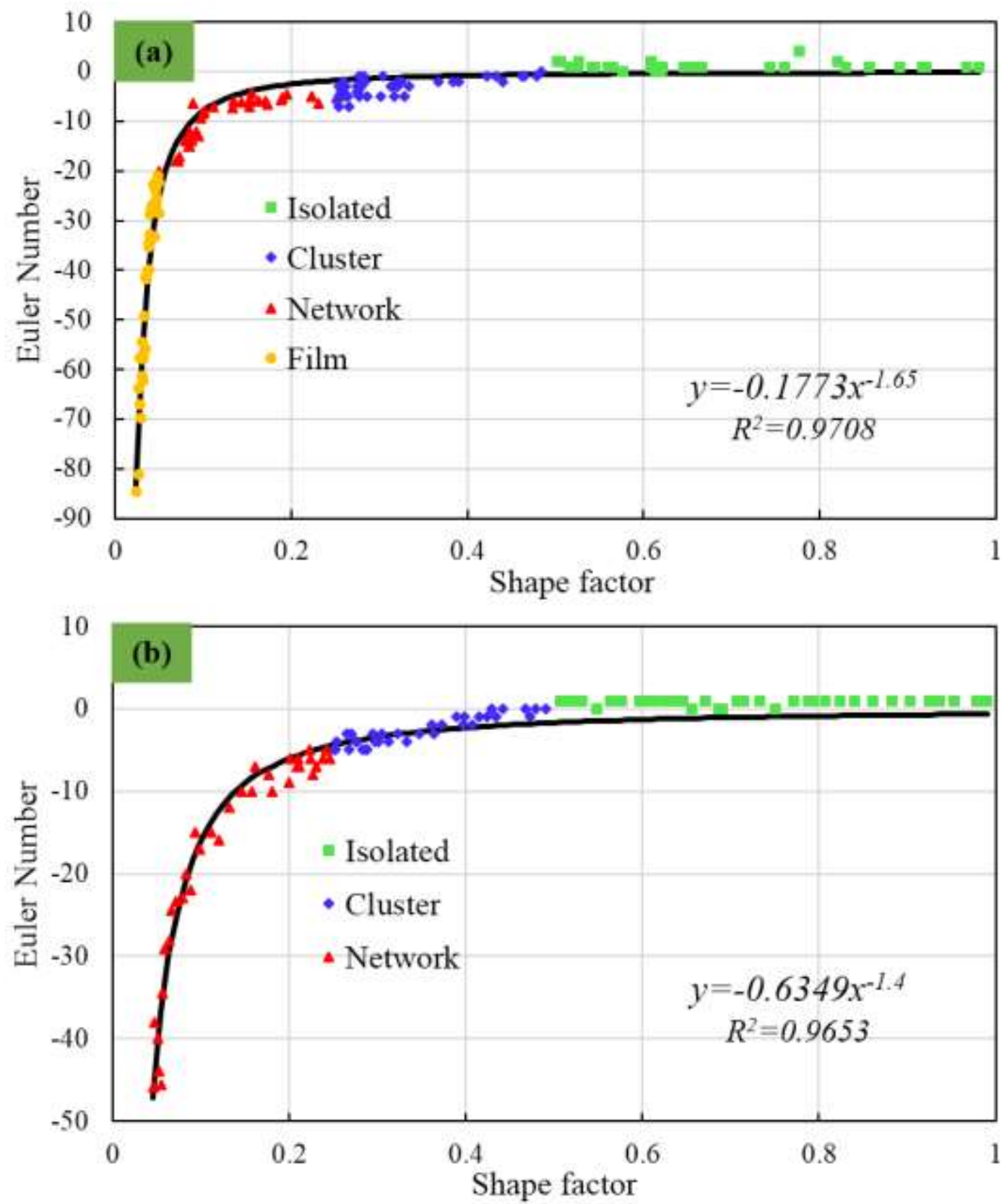

615 Shape factor

$616 \quad$ Fig. 11

617 
Journal of Energy Resources Technology

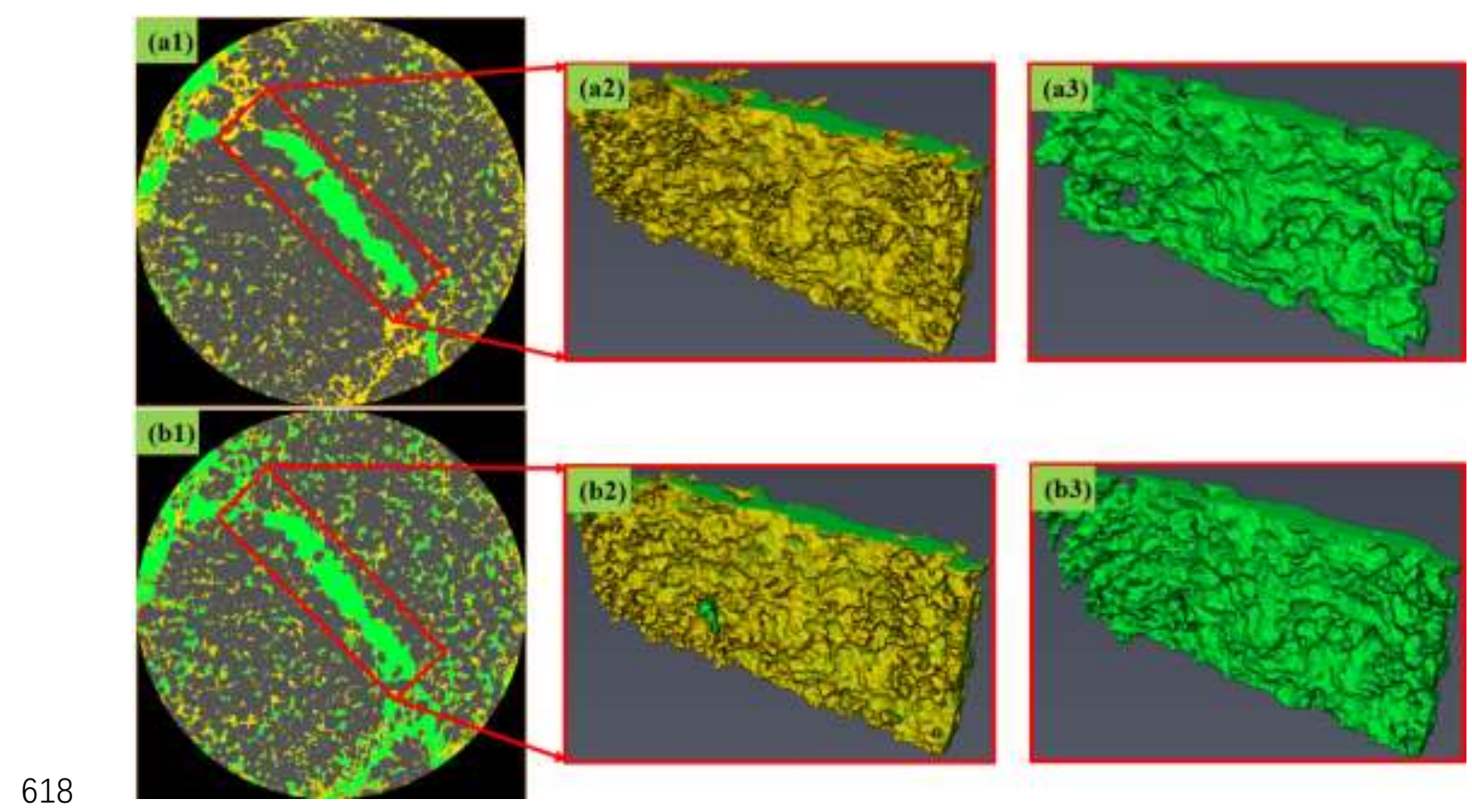

$619 \quad$ Fig. 12

620 

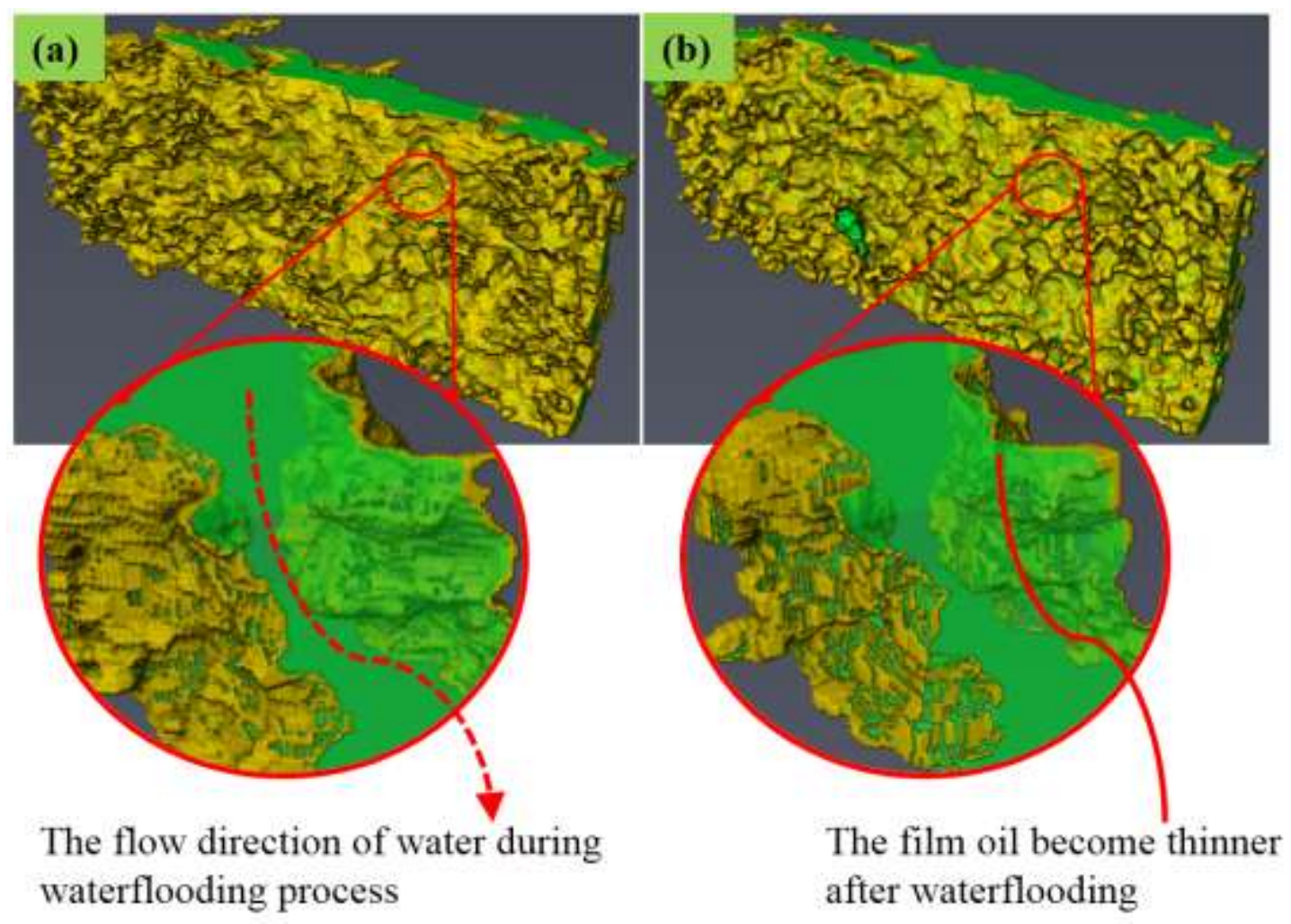

621

Fig. 13

623 
Flow direction



624

625

626

Fig. 14
Flow direction

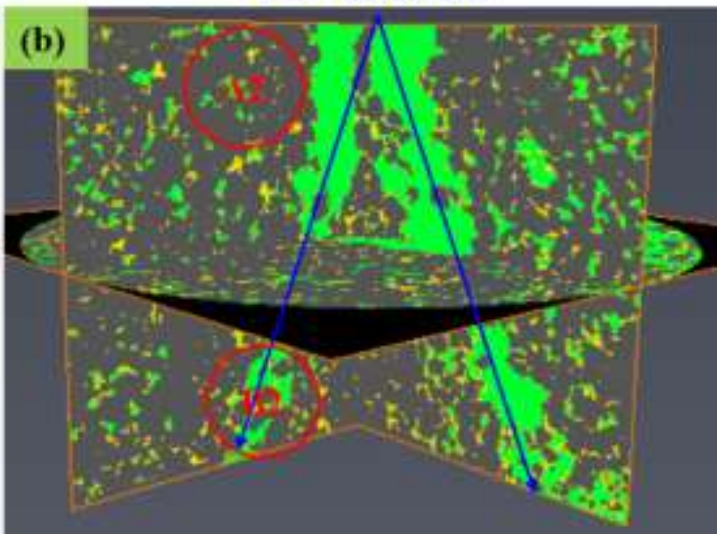


Journal of Energy Resources Technology
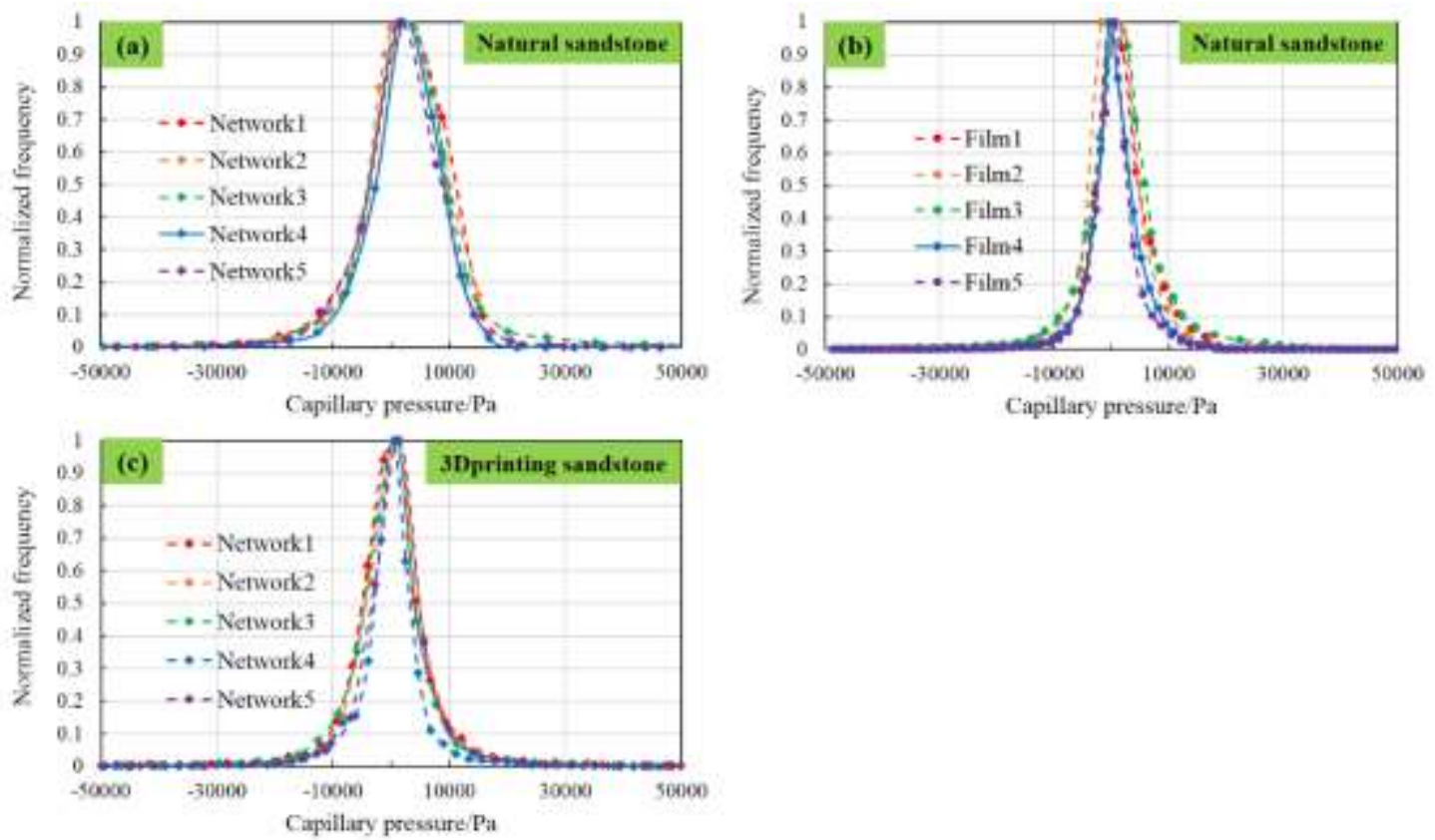

Fig. 15 
Journal of Energy Resources Technology

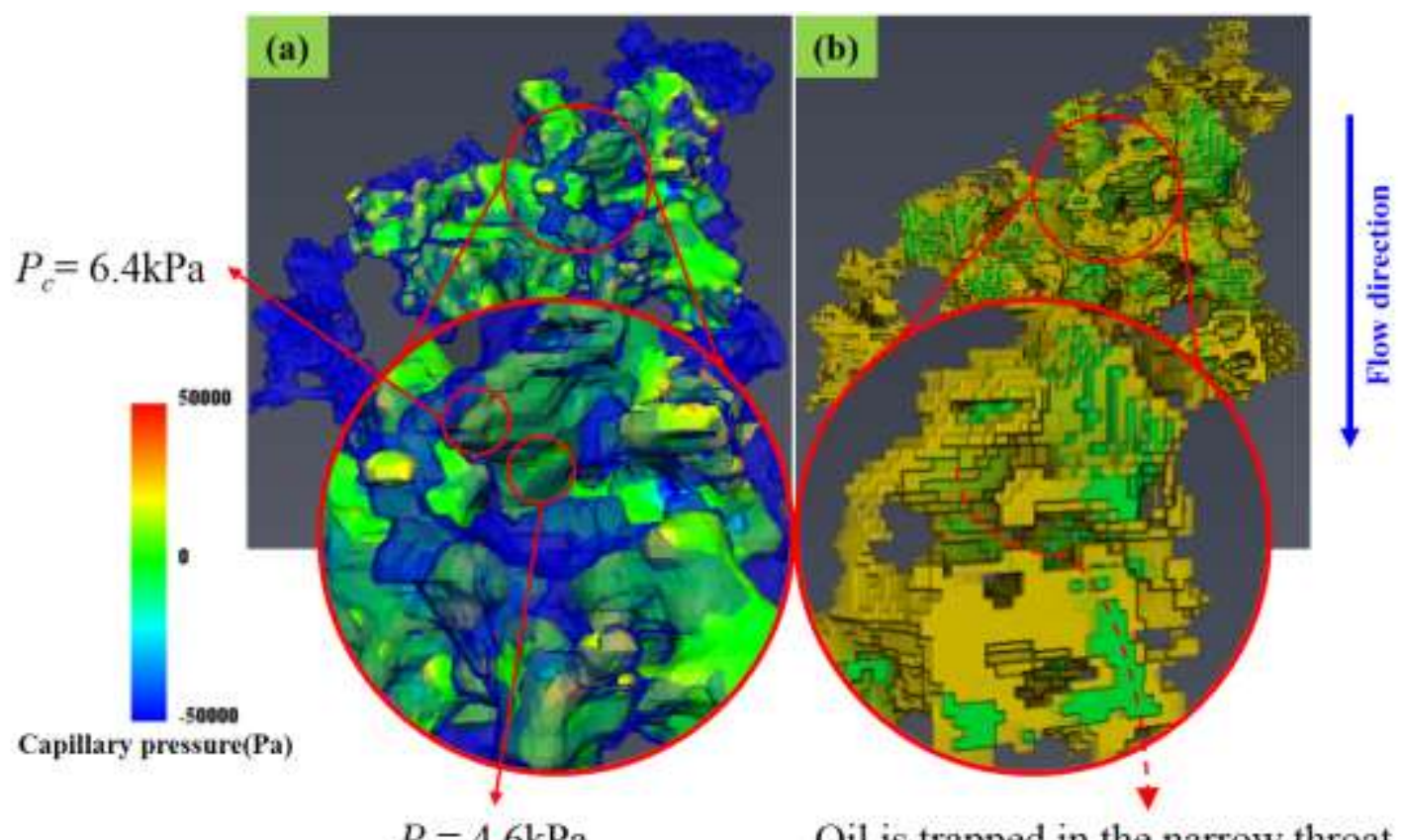

630

$P_{c}=4.6 \mathrm{kPa}$

Oil is trapped in the narrow throat

631 Fig. 16

632 


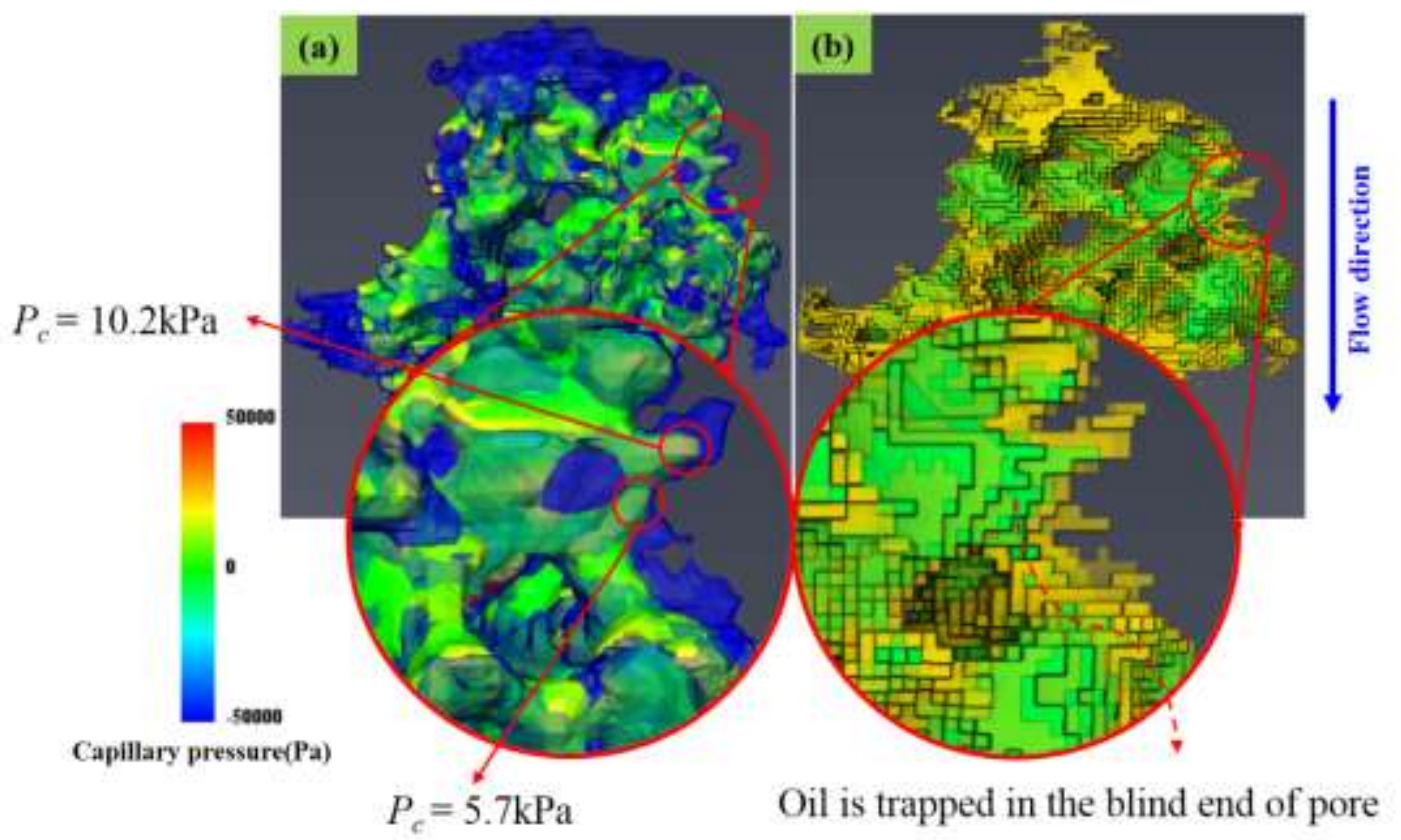

633

Fig. 17

635 
Journal of Energy Resources Technology

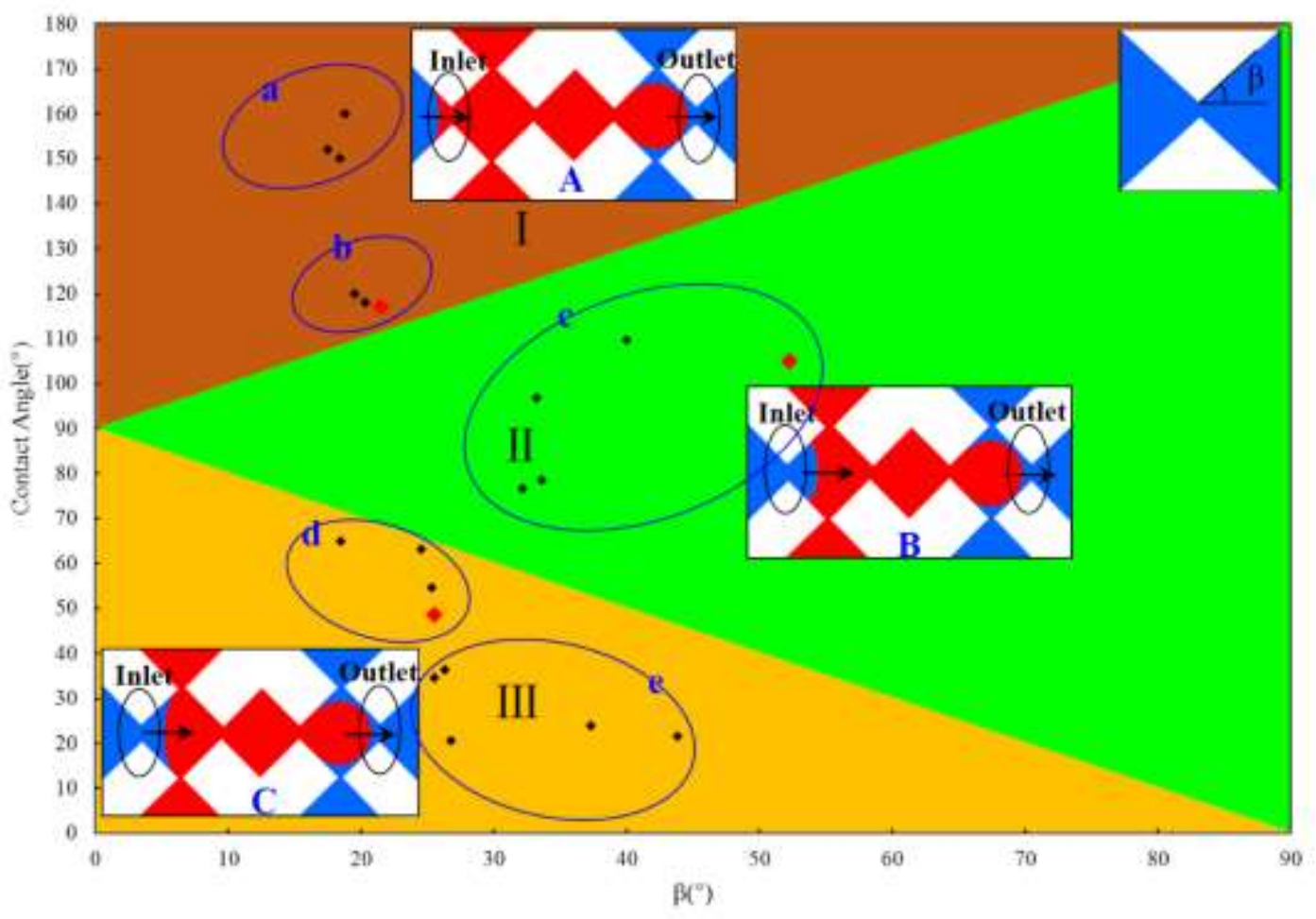

636

637

Fig. 18

638 
Journal of Energy Resources Technology

639

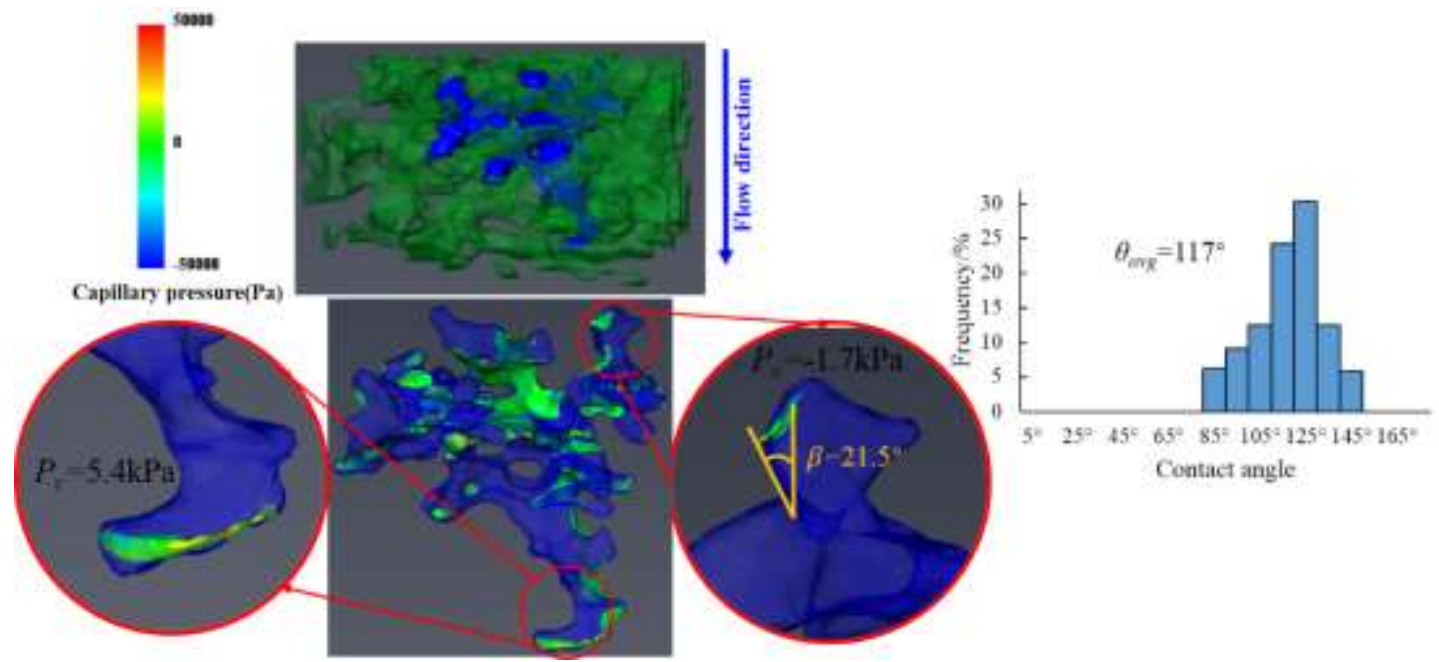

640

Fig. 19

641 
Journal of Energy Resources Technology

642



643

Fig. 20

644 
Journal of Energy Resources Technology

645

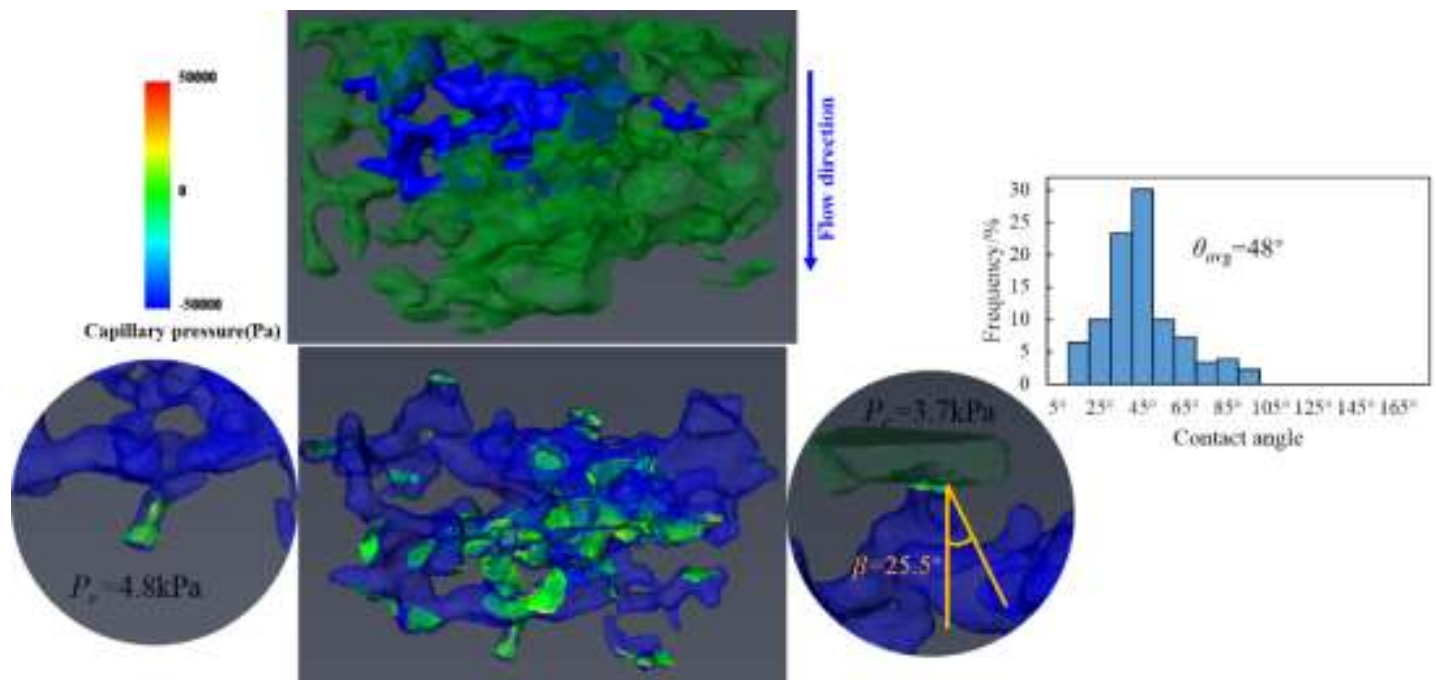

646 Fig. 21

647 
Journal of Energy Resources Technology

648

Table 1

649

\begin{tabular}{lllll}
\hline Sample & Diameter $(\mathrm{mm})$ & Length $(\mathrm{mm})$ & Porosity $(\%)$ & Gas permeability $(\mathrm{mD})$ \\
\hline Natural sandstone & 6 & 5 & 18.40 & 35.8 \\
3D printed sandstone & 6 & 5 & 40.23 & 350.6 \\
\hline
\end{tabular}

650

651 


\section{Journal of Energy Resources Technology}

652

653

\begin{tabular}{llll}
\hline Deionized water $(\mathrm{L})$ & $\mathrm{Nacl}(\mathrm{g} / \mathrm{L})$ & $\mathrm{CaCl} 2(\mathrm{~g} / \mathrm{L})$ & $\mathrm{MgCl} 2(\mathrm{~g} / \mathrm{L})$ \\
\hline 1 & 70 & 6 & 4
\end{tabular}

654

655 
Journal of Energy Resources Technology

656

657

\begin{tabular}{llll}
\hline Residual oil type & Shape factor $(G)$ & Euler $\operatorname{Number}\left(E_{N}\right)$ & Typical residual oil \\
isolated & $G>0.5$ & $E_{N} \geq 1$ & \\
cluster & $0.25<G<0.5$ & $-5 \leq E_{N}<1$ & \\
& & & \\
network & $0.05<G<0.25$ & $-20 \leq E_{N} \leq-5$ & \\
film & $G<0.05$ & $E_{N}<-20$ & \\
\hline
\end{tabular}

658

659 
Journal of Energy Resources Technology

$660 \quad$ Table 4

661

\begin{tabular}{lll}
\hline Sample & Contact angle $<90^{\circ}$ (water-wetted) & Contact angle $>90^{\circ}$ (oil-wetted) \\
\hline Natural sandstone & $21.22 \%$ & $78.78 \%$ \\
3D printed sandstone & $49.82 \%$ & $50.18 \%$ \\
\hline
\end{tabular}

662

663 
Journal of Energy Resources Technology

$664 \quad$ Table 5

\begin{tabular}{lllll}
\hline Sample & Displacement stage & Oil volume $\left(\mu \mathrm{m}^{3}\right)$ & Oil saturation(\%) & Oil recovery(\%) \\
\hline \multirow{2}{*}{ Natural sandstone } & Before waterflooding & $4.37 \times 10^{9}$ & $67.52 \%$ & $/$ \\
& After waterflooding & $3.97 \times 10^{9}$ & $44.92 \%$ & $9.15 \%$ \\
\multirow{3}{*}{ 3D printed sandstone } & Before waterflooding & $2.96 \times 10^{9}$ & $60.13 \%$ & $/$ \\
& After waterflooding & $1.93 \times 10^{9}$ & $39.44 \%$ & $34.80 \%$ \\
\hline
\end{tabular}

665

666 
Journal of Energy Resources Technology

667 Table 6

\begin{tabular}{llll}
\hline Displacement stage & Oil volume $\left(\mu \mathrm{m}^{3}\right)$ & water volume $\left(\mu \mathrm{m}^{3}\right)$ & Oil recovery $(\%)$ \\
\hline Before waterflooding & $1.72 \times 10^{8}$ & $6.14 \times 10^{8}$ & $/$ \\
After waterflooding & $1.31 \times 10^{8}$ & $7.18 \times 10^{8}$ & 23.84 \\
\hline
\end{tabular}

668 